\title{
INFLUENCE OF ANESTHESIA (ETHER, CYCLOPROPANE, SODIUM EVIPAL) ON THE CIRCULATION UNDER NORMAL AND SHOCK CONDITIONS ${ }^{1}$
}

\author{
By H. STANLEY BENNETT, ${ }^{2}$ DAVID L. BASSETT, ${ }^{2}$ AND HENRY K. BEECHER \\ (From the Departments of Pharmacology and Anatomy and the Anesthesia Laboratory \\ of the Harvard Medical School, Boston)
}

(Received for publication June 24, 1943)

In the presence of an injury, anesthesia can aggravate an already existing condition of shock, or if shock is impending, anesthesia can precipitate it. In an attempt to evaluate the importance of several of the circulatory factors involved, we have studied dogs in good condition and in shock (hemorrhage). Particular attention has been given to the influence of varying depths of anesthesia on heart rate, on systolic, diastolic, and mean arterial blood pressure, on central venous pressure, and on blood flow in three vascular beds, femoral, carotid, and mesenteric.

\section{MATERIALS AND METHODS}

Animals. Satisfactory data were obtained from a total of 53 mongrel dogs, weighing about $14 \mathrm{kgm}$. each. Adequate blood flow data were obtained from the following experimental material: 16 dogs received evipal with 17 runs (i.e., change in anesthesia depth from very light to very deep) on 11 dogs in good condition, and 9 runs on 9 dogs in shock; 9 dogs received ether, with 14 runs on 6 dogs in good condition, and 14 runs on 7 dogs in shock; and 11 dogs received cyclopropane, with 24 runs on 10 dogs in good condition and 18 runs on 10 dogs in shock. Occasionally, because of technical difficulties, flow data in a given experiment were not satisfactory and yet the pressure data were good. Accordingly, the pressure data are based upon a larger series than the flow data: evipal pressure data are based upon experiments on 21 dogs; ether, on 21 dogs; and cyclopropane, on 11 dogs.

The animals were heparinized with Connaught Laboratories' heparin before cannulation, and a constant intravenous drip of heparin was maintained throughout the remainder of the experiment.

Anesthesia. Sodium evipal was administered intravenously in 10 per cent solution. Ether was administered initially by open cone induction. The neck was dissected, a tracheal cannula inserted, and ether during the rest of

1 The work described in this paper was done under a contract, recommended by the Committee on Medical Research, between the Office of Scientific Research and Development and Harvard University.

2 Lieutenant, M. C., V(S), U.S.N.R.

Fellow of the National Research Council. the experiment was administered by means of a closed system (Foregger) with carbon dioxide absorption. Dead space was maintained near normal. Cyclopropane was given initially in oxygen through a cone equipped with a rubber diaphragm which fitted snugly around the dog's snout. After induction, cyclopropane anesthesia was maintained as with ether.

After the recording camera was started, the usual procedure was to allow the animal to become lightly anesthetized, as judged by the character of the respiration and the sensitivity of the corneal reflex. As a further index of depth of anesthesia, in some of the experiments, we used the reflex contraction of the semitendinosus muscle in response to electrodal stimulation of the sciatic nerve. The activity of this reflex was a useful guide to anesthesia depth in the animals in good condition, but not a dependable one in the animals in shock. Starting from a state of light anesthesia, the anesthesia was deepened. In the case of evipal, this was accomplished by additional intravenous injection, deepening the anesthesia quickly. The volatile anesthetics were employed so as to produce a condition of deep anesthesia during a period of about 10 to 15 minutes (Figures 4, 5, 7, 8). Administration was terminated when the animal was near the point of respiratory failure. The dog was then allowed to blow off the agent, after which the procedure was repeated.

The standard preparation involved the dissection of the trachea, both carotid arteries, one external jugular vein (sometimes both), the superior mesenteric or portal veins, and one femoral artery. Dissection was done with electrocautery, with meticulous hemostatis in order to reduce blood loss after heparinization. The preliminary induction of anesthesia and the dissection usually consumed about one hour and a half. After dissection, the animal was heparinized and flowmeter cannulae inserted into the femoral and carotid arteries and superior mesenteric vein. As a rule, the flowmeter cannulation required that the blood flow through the vessel in question be interrupted for a period of 1 to 3 minutes. Cannulae were also inserted in one carotid artery and in the jugular vein and connected with the pressure manometers for recording. The heater currents and counter currents (see Appendix) were then set for each of the 3 flowmeters, and the recording camera started. These procedures consumed an additional hour; thus about $21 / 2$ hours elapsed from the time of anesthesia induction until recording was started. The preparation of the animals was necessarily time consuming and involved considerable dissection and trauma, yet at the end of this, 
our subjects were as a rule in excellent condition with a mean arterial pressure of $120 \mathrm{~mm}$. $\mathrm{Hg}$ or better when the recording began, and characteristically remained so until routine bleeding was started.

Pressures. Arterial pressure was recorded from the cannulated carotid artery. Central venous pressure was measured through a flexible plastic tube inserted in the right external jugular vein and passed down so that its open tip lay near the entrance of the superior vena cava into the right atrium. Zero pressure base-lines for arterial and venous pressures were taken from the same level by opening the chest of the dog after death, severing the thoracic aorta and vena cava, filling the chest with water up to the level of the entrance of the venae cavae into the atrium, and balancing the mercury columns against this level, a modification of a method recommended by Green (1).

Both arterial and venous pressures were recorded optically by means of glass membrane manometers similar to those described by Green (2). The natural period frequency of the arterial systems (approximately 150 per second) was such as to give a satisfactorily accurate recording of peak systolic and diastolic pressures. A plastic tubing, "Saran" (Dow Chemical Company), was used for the hydraulic connections between manometer and cannula. This tubing was essentially non-distensible, sufficiently flexible, and did not crystallize and break after repeated bending.

In order to record at will either full pulse pressures or integrated mean pressures, a hydraulic damping system was installed (Figure 1). The single lead from stopcock A was connected to the cannula by Saran tubing. When full pulse pressures were to be recorded, stopcock A was turned to transmit the pressure wave through the upper of the 2 parallel arms directly to the glass manometer $\mathrm{E}$, and stopcock B was turned off. To obtain records of damped pressure, stopcock $A$ was turned to transmit the pressure wave through the lower of the 2 arms, in which a plug of glass wool (F) had been inserted. At the same time, stopcock B was opened in order to connect an airbell above the stopcock to the system. Stopcock D was kept closed at all times, except when the amount of air in the airbell was to be adjusted for purposes of varying the time characteristics of the damped record. Stopcock $C$ was used solely to connect the manometer to a pressure bottle and mercury manometer for purposes of calibration. The entire system was kept filled with fluid except for the air bubble which was confined above stopcock B. These damped pressures did not, of course, represent an average of systolic and diastolic pressures, but rather an integrated mean equivalent to half the area under the pressure curve during a time constant which could be varied with the size of the airbell. The advantages of this apparatus over a well-damped mercury manometer lie in ready adjustability of the degree of damping, and easy adaptability to the recording of full pulse wave forms or mean pressures from the same manometer. It works equally well for arterial or central venous pressure. Typical tracings of full pressure and integrated mean (damped) pressures, with conversions from one to the other, are shown in Figure 3.

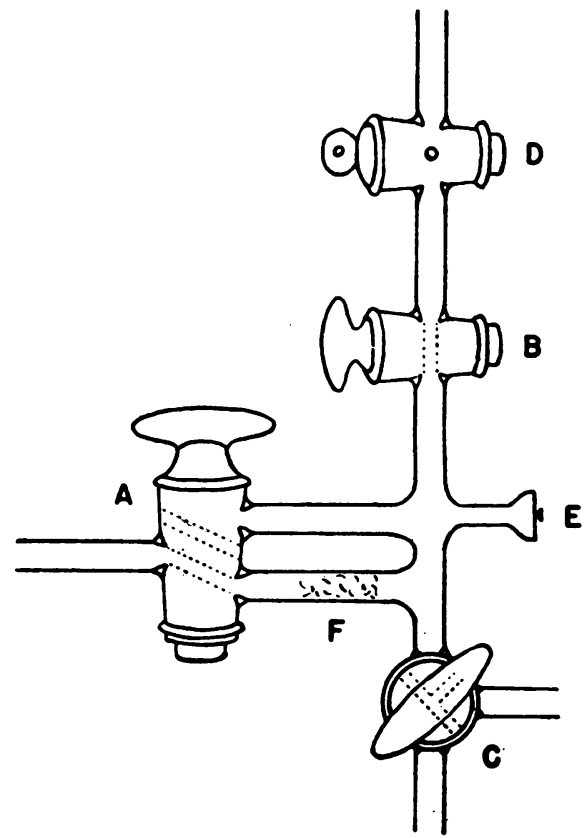

Fig. 1. Diagram of Hydraulic System for Obtaining Either full Pulse Pressure Tracings or Integrated Mean Pressures

For explanation see text.

Heart rates and pressures were counted or measured from the optical records. We agree with Werle, Cosby, and Wiggers (3) that because of arrhythmias and variations of systolic and diastolic pressures with individual heart beats, no absolute values for these figures can be taken. In order to minimize the arrhythmic effects of respiration, heart rates were counted for periods which included several respiratory cycles, 10 seconds usually being sufficient. Mean systolic and diastolic figures were estimated from the numerous peaks occurring in a similar period. Mean arterial and venous pressures were measured accurately.

Blood flow. This was recorded optically by means of the heated thermocouple flowmeter of Bennett, Sweet, and Bassett, described in an appendix to this paper. The instrument was improved and refinements added from time to time during the course of the study. Hence, flow records taken early in the study (evipal) are not as reliable quantitatively as those obtained with ether and cyclopropane; but directional changes in the case of evipal are valid as presented. In interpreting the data, due attention was paid to the limitations and inaccuracies of the flow recording method as discussed by Bennett, Sweet, and Bassett. Frequent checks were made for changes in parasitic currents, and any changes found were corrected. The points at which these checks were made show as small breaks in the flow records (Figures 6,9 ). When routine corrections were made, a shift appeared in the restored line after the break.

As shown below, there was considerable variation from dog to dog in absolute flow values under comparable con- 
ditions when recorded by this method. The majority of the values scattered closely around the mean, but occasional flows far above or below this figure were recorded. Technical errors may be involved in these aberrant values, but changes in their flow on deepening anesthesia showed percentage changes closely in line with those nearer to the mean. Hence, it appeared justifiable to include these flow records in our series, since the results did not conflict with those taken with absolute flow values near to the mean. Possible technical errors in flow recording throw some doubt on the validity of the absolute values for flow, as described in the appendix; but the means cited are not in great disagreement with values for comparable vessels obtained by other methods (4 to 8).

We should like to preface our presentation of the flow data with the clear statement that we realize fully the hazards of blood flow measurement. However, the results are sufficiently consistent to give some basis for conviction as to validity, and pending the development of better methods for recording blood flow, it appears to be justifiable to present the results tentatively, with the hope that they can be checked subsequently when blood flow can be measured with more accuracy.

Impedance calculations. Impedance calculations were made to determine whether or not given flow changes were those to be expected from changes in pressure. An increase in impedance ordinarily indicates vasoconstriction, while a decrease in impedance would denote vasodilatation. The impedance figures are subject to the same errors as those for flow.

From the measurements of flow in a given vascular bed and the difference between the mean arterial and venous pressures, the hydraulic impedance of the bed was calculated by the formula,

\section{Mean Arterial Pressure (mm. Hg) - Mean Central Venous}

Impedance $=\frac{\text { Pressure }(\mathrm{mm} . \mathrm{Hg})}{\text { Mean Flow in cc. per second }}$ $K$

This calculation is derived from Poiseuille's equation and is similar to the formula commonly used for calculating "peripheral resistance," but differs from the usual formula in that central venous pressure is taken into account, and the word "impedance" is used instead of resistance. Consideration of venous pressure yields a figure of increased accuracy, since, as Poiseuille showed, it is actually the "difference" in hydraulic pressure which provides the moving force to fluid, and in the case of the peripheral circulation, this difference is the difference between the mean central arterial and mean central venous pressures. Both pressures must necessarily be expressed in the same units and with reference to the same level. In dogs, the venous pressure factor makes for only a small error when the animals are in good condition, but in shock, when the mean arterial pressure is low, the error arising from neglect of the venous pressure factor may be as high as 10 to 15 per cent.

The term "impedance" seemed preferable to "resistance" because the animal circulation, with its fluctuating pressures and elastic vessels, bears a close analogy to an
A.C. circuit, where inductances and capacitances may produce a lag between voltage and current fluctuations. The term "resistance" which implies a certain special relationship between pressure and flow, properly applies only to hydraulic systems with perfectly rigid walls or with steady pressure head, or both.

Shock production. After one or more "control" runs from light anesthesia to deep and back again, with the animal in good condition, the animal was bled from an artery or from a vein, small amounts at a time, depending upon the condition of the animal. Initially, this usually varied from one-half to one per cent of the body weight with subsequent bleeding at 20 to 30 -minute intervals in one-quarter per cent of body weight quantity, depending upon the animal's condition. Bleeding was varied so that over a period of an hour or more the blood pressure would reach a shock level, which was arbitrarily defined as a mean arterial pressure of $70 \mathrm{~mm} \mathrm{Hg}$, or below. There was always oozing from cut surfaces after heparinization, and at times, the blood lost in this way was considerable, amounting to over $100 \mathrm{cc}$. during an experiment of several hours. Blood loss through oozing was as far as possible collected and measured, and included in the figures for total blood loss. Undoubtedly, the dissection and oozing contributed to the shock induced by bleeding. Hence, the shock here is not pure hemorrhagic shock, but is complicated by some trauma from dissection and the necessary intestinal exposure and manipulation and in part by burn from the cautery. When the animal had been put into shock the anesthesia was deepened through one or more cycles as before. This was continued until the animal died.

Records of pressures and of flows were taken continuously from the cannulated vessels. The flow recording beams were checked about every 3 minutes for drift due to variables mentioned before, and any drift found was corrected. The arterial pressure recording system was shifted from damped to undamped at frequent (about 3-minute) intervals during the experiment, allowing us to follow closely changes in systolic, diastolic, and mean pressures. The central venous pressure was usually recorded as damped.

\section{RESULTS AND DISCUSSION}

The tables below summarize the data on which the curves (Figures 2, 4, 5, 7, 8) were based. Flow and impedance factors charted and included are expressed in terms of percentage of flow or impedance under conditions of light anesthesia. This afforded the best means of comparing these factors from animal to animal. The averages were computed by taking the flows and impedances during each run at each point in terms of percentage of control flow or impedance value under light anesthesia, and averaging the percentages so obtained. Standard errors of the means are included. Pressure $(\mathrm{mm} . \mathrm{Hg}$ ) and 
heart rate data were averaged in terms of absolute values. The points along the time scales during deepening of anesthesia were taken according to the fraction of time elapsed between the point of administering the anesthetic and the time of its termination. During recovery, readings were taken on a straight time basis.

The figures for absolute flow showed considerable variation from dog to dog under comparable conditions, perhaps due in part to variations in body size of dogs and in variations of relative size of head or other members with the various breeds and mixtures that were used. We have corrected our flows and impedances for body surface, believing that individual anatomical differences would be balanced amongst the several dogs in our series.

Flow in cc. per second in femoral and carotid arteries and mesenteric veins was corrected by dividing the flow by body surface in square meters and the corresponding impedances corrected by multiplying by body surface. Body surface was calculated from the body weight by the Meeh formula.

Body Surface in Meters ${ }^{2}=\mathbf{0 . 1 1 2}$

\section{$\times$ Kilograms Body Weight ${ }^{2 / 2}$}

Table VII shows comparisons of flows in cc. per second per sq. meter of body surface and impedances $X$ sq. meters of body surface, the impedances calculated as in the formula shown above, with the constant taken as 1 . The figures are averages of corrected flows and impedances from all our dogs under ether or cyclopropane, the values corresponding to those in the control period of light anesthesia before deepening (Figures 4, 5, 7, 8; Tables III, IV, V, VI).

It will be observed that the mean flow and impedance values shown in Table VII have large standard errors. These large standard errors raise the possibility that technical errors in flow recording may be operative in some cases. As explained by Bennett, Sweet, and Bassett (in the Appendix), opportunity for technical error in the flowmeter used is considerable. The values referred to indicate that this flowmeter has detected no significant differences between femoral, carotid, and mesenteric flows and impedances in dogs in good condition under light cyclopropane anesthesia, as compared with flows in the same vessels under light ether anesthesia when one small group of animals is compared with another group. A comparison of the two agents in a given animal might still show characteristic differences. It would be desirable to repeat the measurements when more accurate methods of recording blood flow become available, as it would also be desirable to study the effects of two agents in the same animal. The percentage changes of blood flow and impedance are more consistent and probably more useful than the absolute values shown.

\section{Sodium evipal}

Evipal was the first of the agents studied in the course of these experiments, when the flow recording technic was less accurate quantitatively than later. However, directional changes in flow after evipal injection were consistent, and

TABLE I

Sodium evipal-dog in good condition

Means with standard errors

\begin{tabular}{|c|c|c|c|c|c|c|c|c|c|}
\hline & \multirow[b]{2}{*}{$\begin{array}{c}\text { Minutes } \\
\text { after } \\
\text { injection }\end{array}$} & \multicolumn{3}{|c|}{ Arterial blood pressure } & \multirow[b]{2}{*}{$\begin{array}{l}\text { Venous } \\
\text { pressure }\end{array}$} & \multicolumn{3}{|c|}{ Flows in percentages of control level } & \multirow[b]{2}{*}{$\begin{array}{c}\text { Heart } \\
\text { rate }\end{array}$} \\
\hline & & Systolic & Diastolic & Mean & & $\begin{array}{c}\text { Femoral } \\
\text { artery }\end{array}$ & $\begin{array}{l}\text { Carotid } \\
\text { artery }\end{array}$ & $\begin{array}{l}\text { Superior } \\
\text { mesenteric } \\
\text { or portal } \\
\text { vein }\end{array}$ & \\
\hline Control-before injection & & $133 \pm 5$ & $\begin{array}{c}m m . H g \\
96 \pm 5\end{array}$ & $105 \pm 4$ & $\begin{array}{c}m m . H_{g} \\
-3.3 \pm 0.7\end{array}$ & 100 & 100 & 100 & $\begin{array}{c}\text { per minute } \\
171 \pm 14\end{array}$ \\
\hline
\end{tabular}

Sodium evipal-10 per cent solution $1.4 \pm 0.1 \mathrm{cc}$. i.v.

\begin{tabular}{l|r|r|r|l|l|l|l|l|l}
\hline $\begin{array}{l}\text { Maximum effect } \\
\text { Recovery }\end{array}$ & $1.0 \pm 0.2$ & $90 \pm 9$ & $52 \pm 6$ & $69 \pm 10$ & $-2.0 \pm 0.8$ & $43 \pm 13$ & $53 \pm 11$ & $61 \pm 6$ & $183 \pm 18$ \\
& $4.0 \pm 0.3$ & $105 \pm 8$ & $77 \pm 6$ & $87 \pm 2$ & $-2.6 \pm 0.6$ & $50 \pm 15$ & $70 \pm 10$ & $78 \pm 9$ & $184 \pm 13$ \\
\hline
\end{tabular}




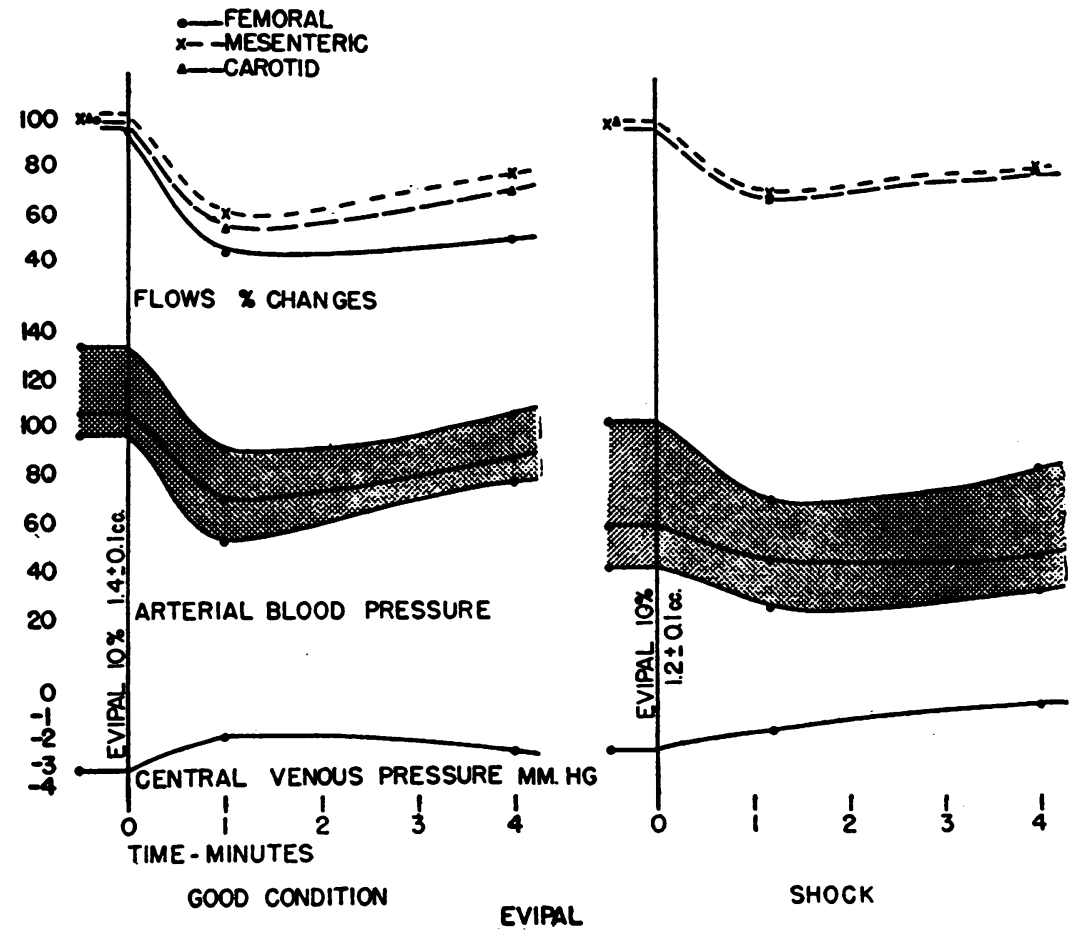

Fig. 2. Acute Effects of Evipal Injection on Flows and Pressures in Dogs in Good Condition and in Shock

Points are averages of pressures in $\mathrm{mm} . \mathrm{Hg}$ or of flows in percentages of control values before injection (see Tables I and II).

since, at this time, our primary interest is in qualitative effects, we have included these data. We frequently checked flow changes in an artery with simultaneous records from the corresponding vein (Figure 3) and since the correlation was good, we regard our recorded changes as accurate in direction and approximately correct as to percentage, and not due to changes in pulse wave form or artefacts which would scarcely be likely to affect both artery and vein alike.

Variations in anesthesia depth. The results of deepening the anesthesia with evipal in animals, both in good condition and in shock, can be summarized very briefly (Tables I, II, Figure 2): reduction in systolic, diastolic, and mean arterial pressures; rise in central venous pressure;

TABLE II

Sodium evipal-dog in shock

Means with standard errors

\begin{tabular}{|c|c|c|c|c|c|c|c|c|c|}
\hline & \multirow[b]{2}{*}{$\begin{array}{l}\text { Minutes } \\
\text { after } \\
\text { injection }\end{array}$} & \multicolumn{3}{|c|}{ Arterial blood pressure } & \multirow[b]{2}{*}{$\begin{array}{l}\text { Venous } \\
\text { pressure }\end{array}$} & \multicolumn{3}{|c|}{ Flows in percentages of control level } & \multirow[b]{2}{*}{$\begin{array}{c}\text { Heart } \\
\text { rate }\end{array}$} \\
\hline & & Systolic & Diastolic & Mean & & $\begin{array}{c}\text { Femoral } \\
\text { artery }\end{array}$ & $\begin{array}{l}\text { Carotid } \\
\text { artery }\end{array}$ & $\begin{array}{c}\text { Superior } \\
\text { mesenteric } \\
\text { or portal } \\
\text { vein }\end{array}$ & \\
\hline Control-before injection & & $102 \pm 9$ & $\begin{array}{c}m m . H_{g} \\
41 \pm 4\end{array}$ & $58 \pm 4$ & $\begin{array}{c}m m . H_{g} \\
-2.6 \pm 0.4\end{array}$ & & 100 & 100 & $\begin{array}{c}\text { per minute } \\
216 \pm 10\end{array}$ \\
\hline
\end{tabular}

Sodium evipal-10 per cent solution $1.2 \pm 0.1 \mathrm{cc}$. i.v.

\begin{tabular}{l|l|l|l|l|l|l|l|l|l}
\hline $\begin{array}{l}\text { Maximum effect } \\
\text { Recovery }\end{array}$ & $1.2 \pm 0.2$ & $69 \pm 7$ & $24 \pm 3$ & $31 \pm 4$ & $-2.6 \pm 0.4$ & & $67 \pm 10$ & $71 \pm 5$ & $219 \pm 19$ \\
\hline
\end{tabular}



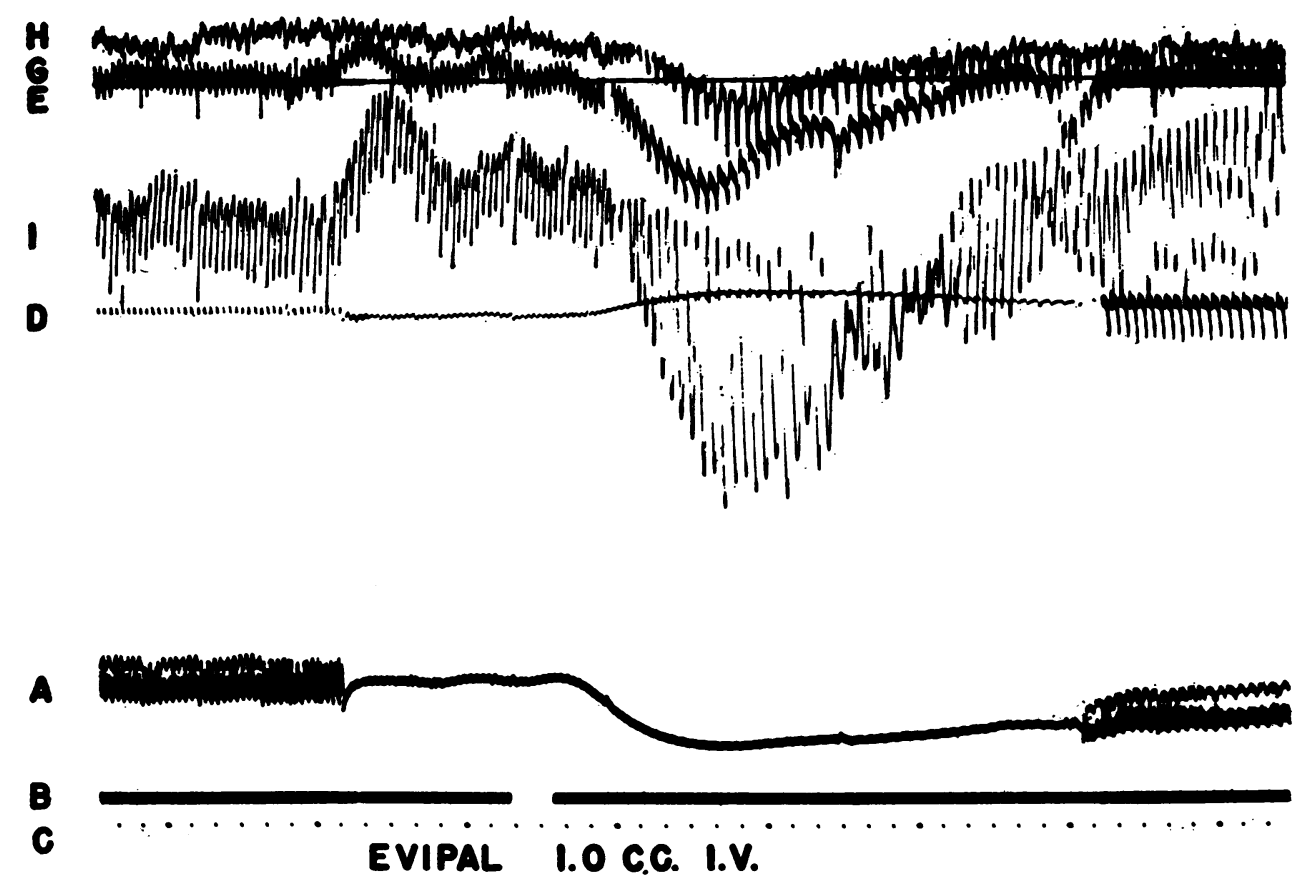

Fig. 3. Optical Tracing of Acute Effects of Injection of Evipal, 10 per cent Solution, 1.0 cc. Intravenously, at Break in Arterial Pressure Base-Line

Key to figures in all tracings. $A=$ Arterial blood pressure, either undamped or damped. $\mathbf{B}=$ Arterial pressure base line. $\quad \mathbf{C}=$ Time: small marks, 10 seconds; large marks, 1 minute. $\mathrm{D}=$ Central venous pressure, either damped or undamped. $\mathrm{E}=$ Venous pressure base-line. $F=$ Femoral artery flow. $G=$ Carotid artery flow. $H=$ Superior mesenteric vein flow. $\mathrm{I}=$ Jugular vein flow. $\mathrm{J}=$ Flowmeter base-line.

diminution in flow through the carotid, femoral, and mesenteric vascular beds, as recorded either in the artery or in the vein; no consistent changes in heart rate. Impedance calculations were not made with the evipal flow data, since these flow values were not considered dependable in a quantitative sense.

The mean arterial pressure changes found here confirm those described by Das (9) and others. The maximum effect on the circulation usually occurred about a minute after the intravenous injection, with all components recovering gradually thereafter over a period of many minutes, of tentimes not reaching again the original control levels.

The only important difference between the acute effects of evipal injections in animals in good condition as compared with animals in shock was that in shock, recovery from the effects took considerably longer than in animals in good condition and was almost always incomplete. These effects and differences are summarized in Tables I and II and charted in Figure 2 with time relationships shown. A typical record of simultaneous flow and pressure changes is shown in Figure 3.

Progressive changes with shock. As shock progressed (Figures 11, 12) with the subject under light evipal anesthesia, the systolic, diastolic, and mean arterial pressures fell as expected. Under evipal, a curious difference from the other agents was apparent: Starting from an initial normal pulse pressure, as shock progressed, the pulse pressure became progressively larger as a result of the diastolic pressure falling more rapidly than the systolic. The widest pulse pressure was found usually with a mean arterial pressure of 40 to $50 \mathrm{~mm}$. $\mathrm{Hg}$. During the agonal stage, the pulse pressure narrowed rather rapidly.

\section{Ether}

Variations in anesthesia depth. When flow and pressure were recorded in animals in good 


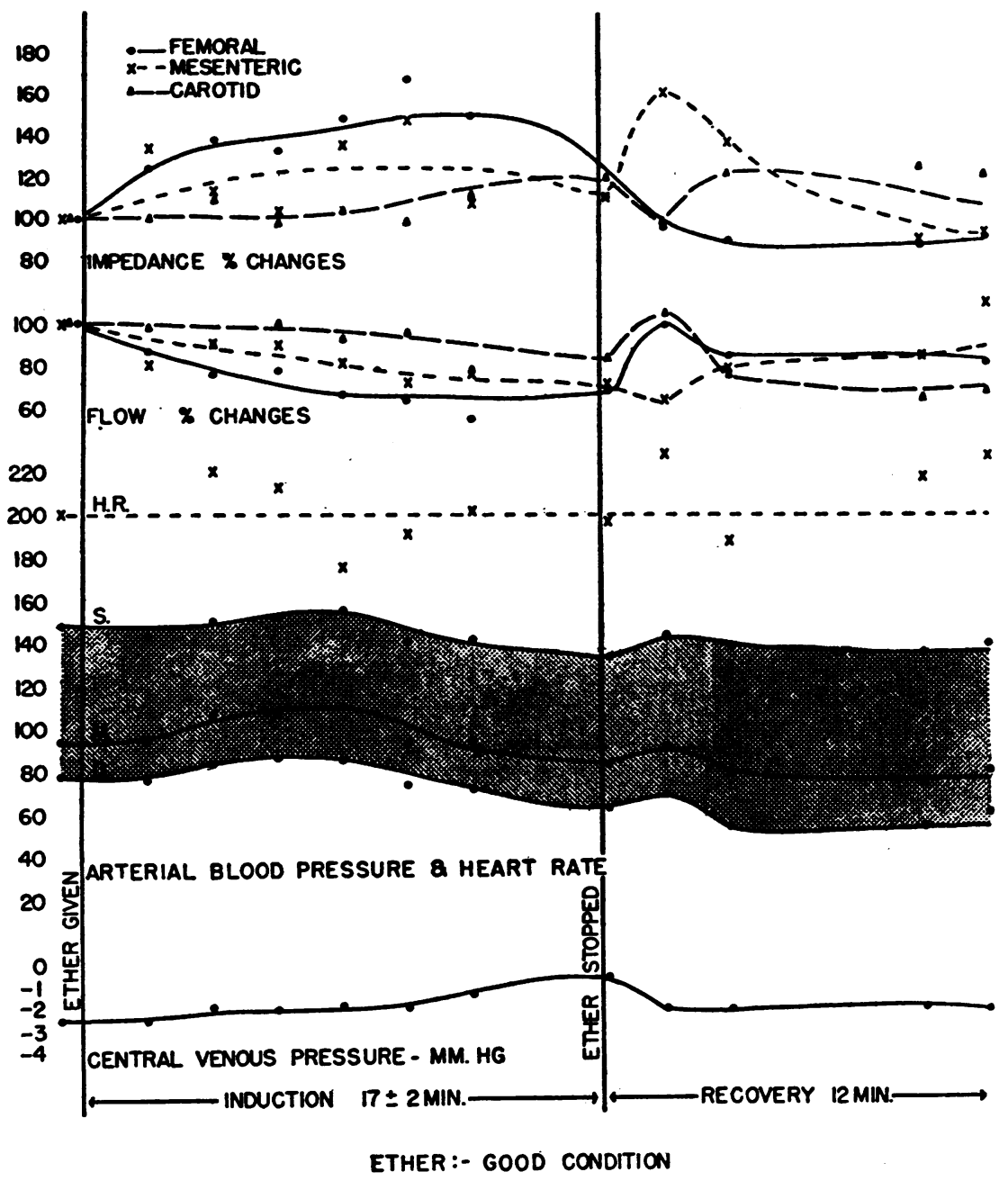

Fig. 4. Pressure, Flow, and Impedance Changes in Dogs in Good Condition Under Ether Anesthesia, When Carried from a Control Point Under Very Light Anesthesia to a Deep Level at or Close to Respiratory Failure

The actual time of ether administration varied somewhat from dog to dog, and points have been charted along the abscissa according to the fraction of the time elapsed between the point of starting ether and the time of termination. Abscissae during the recovery period are taken on a straight time basis (see Table III).

condition under light ether anesthesia, and the level of anesthesia then deepened by giving ether until respiratory failure was approached or achieved, the following changes were observed (Table III, Figures 4, 6A): The central venous pressure progressively rose; the systolic, diastolic, and mean arterial pressures usually rose somewhat initially and then fell; blood flow in the femoral and carotid arteries and in the superior mesenteric vein tended to diminish; the hydraulic impedance in these vascular beds increased. The reduction in flow with deepening ether anesthesia confirms a similar observation by Mann, Herrick, Essex, and Baldes (10). The rise in arterial blood pressure found early on deepening the anesthesia probably corresponds to a similar rise described by McAllister and Root (11).

In animals in good condition, discontinuance of the ether supply brought about the following changes: The central venous pressure fell rather rapidly towards the original level. The arterial 
pressure recovered rapidly, often rebounding or more before tapering off at a stable level; coninitially above the level at which it finally sta- versely, the mesenteric vein flow tended to bilized. Flow in femoral and carotid arteries show a decrease followed by recovery (Figures 4, usually showed transient increases for a minute $6 \mathrm{~B}$ ). The hydraulic impedance of femoral and

TABLE III

Ether-dog in good condition

Means with standard errors

\begin{tabular}{|c|c|c|c|c|c|c|c|c|}
\hline & \multicolumn{3}{|c|}{ Arterial blood pressure } & \multirow[b]{2}{*}{ Venous pressure } & \multicolumn{3}{|c|}{ Flows in percentages of control level } & \multirow[b]{2}{*}{ Heart rate } \\
\hline & Systolic & Diastolic & Mean & & $\begin{array}{c}\text { Femoral } \\
\text { artery }\end{array}$ & $\begin{array}{l}\text { Carotid } \\
\text { artery }\end{array}$ & $\begin{array}{c}\text { Superior } \\
\text { mesenteric } \\
\text { or portal vein }\end{array}$ & \\
\hline $\begin{array}{l}\text { Control } \\
\text { Point } 1\end{array}$ & $148 \pm 12$ & $\begin{array}{l}m m . H g \\
78 \pm 8\end{array}$ & $94 \pm 9$ & $\begin{array}{c}m m . H g \\
-2.6 \pm 0.1\end{array}$ & $100 \pm 0$ & $100 \pm 0$ & $100 \pm 0$ & $\begin{array}{l}\text { per minute } \\
200 \pm 10\end{array}$ \\
\hline \multicolumn{9}{|c|}{ Ether started } \\
\hline $\begin{array}{l}2 \\
3 \\
4 \\
5 \\
6 \\
7\end{array}$ & $\begin{array}{l}143 \pm 12 \\
150 \pm 13 \\
152 \pm 10 \\
155 \pm 9 \\
140 \pm 8 \\
141 \pm 8\end{array}$ & $\begin{array}{l}76 \pm 7 \\
83 \pm 6 \\
86 \pm 5 \\
85 \pm 3 \\
73 \pm 1 \\
71 \pm 1\end{array}$ & $\begin{array}{c}94 \pm 10 \\
107 \pm 8 \\
107 \pm 6 \\
110 \pm 5 \\
93 \pm 3 \\
94 \pm 6\end{array}$ & $\begin{array}{l}-2.6 \pm 0.3 \\
-2.0 \pm 0.3 \\
-2.1 \pm 0.3 \\
-2.0 \pm 0.3 \\
-2.1 \pm 0.1 \\
-1.5 \pm 0.3\end{array}$ & $\begin{array}{l}87 \pm 13 \\
76 \pm 10 \\
77 \pm 11 \\
67 \pm 9 \\
64 \pm 11 \\
55 \pm 15\end{array}$ & $\begin{array}{r}97 \pm 4 \\
91 \pm 3 \\
100 \pm 8 \\
93 \pm 5 \\
96 \pm 7 \\
78 \pm 9\end{array}$ & $\begin{array}{l}80 \pm 15 \\
92 \pm 5 \\
91 \pm 6 \\
82 \pm 7 \\
73 \pm 12 \\
77 \pm 6\end{array}$ & $\begin{array}{l}221 \pm 40 \\
203 \pm 2 \\
176 \pm 28 \\
191 \pm 10 \\
202 \pm 19\end{array}$ \\
\hline \multicolumn{9}{|c|}{ Ether stopped } \\
\hline $\begin{array}{r}8 \\
9 \\
10 \\
11 \\
12\end{array}$ & $\begin{array}{l}133 \pm 2 \\
143 \pm 8 \\
138 \pm 8 \\
134 \pm 7 \\
139 \pm 3\end{array}$ & $\begin{array}{l}62 \pm 8 \\
68 \pm 5 \\
53 \pm 8 \\
53 \pm 7 \\
60 \pm 14\end{array}$ & $\begin{array}{l}83 \pm 7 \\
91 \pm 6 \\
78 \pm 7 \\
74 \pm 7 \\
80 \pm 11\end{array}$ & $\begin{array}{l}-0.7 \pm 0.4 \\
-2.2 \pm 0.7 \\
-2.2 \pm 0.4 \\
-2.1 \pm 0.3 \\
-2.2 \pm 0.3\end{array}$ & $\begin{array}{r}69 \pm 9 \\
100 \pm 13 \\
85 \pm 11 \\
85 \pm 10 \\
82 \pm 11\end{array}$ & $\begin{array}{r}84 \pm 18 \\
106 \pm 23 \\
76 \pm 17 \\
65 \pm 13 \\
68 \pm 12\end{array}$ & $\begin{array}{c}72 \pm 9 \\
64 \pm 13 \\
79 \pm 21 \\
85 \pm 7 \\
111 \pm 30\end{array}$ & $\begin{array}{l}197 \pm 15 \\
229 \pm 7 \\
187 \pm 17 \\
218 \pm 14 \\
228 \pm 18\end{array}$ \\
\hline
\end{tabular}

TABLE IV

Ether-dog in shock

Means with standard errors

\begin{tabular}{|c|c|c|c|c|c|c|c|c|}
\hline & \multicolumn{3}{|c|}{ Arterial tlood pressure } & \multirow[b]{2}{*}{ Venous pressure } & \multicolumn{3}{|c|}{ Flows in percentages of control level } & \multirow[b]{2}{*}{ Heart rate } \\
\hline & Systolic & Diastolic & Mean & & $\begin{array}{c}\text { Femoral } \\
\text { artery }\end{array}$ & $\begin{array}{l}\text { Carotid } \\
\text { artery }\end{array}$ & $\begin{array}{l}\text { Superior } \\
\text { mesenteric } \\
\text { or portal vein }\end{array}$ & \\
\hline $\begin{array}{l}\text { Control } \\
\text { Point } 1\end{array}$ & $100 \pm 4$ & $\begin{array}{c}m m \cdot H g \\
37 \pm 4\end{array}$ & $56 \pm 3$ & $\begin{array}{c}m m . H g \\
-3.5 \pm 0.3\end{array}$ & $100 \pm 0$ & $100 \pm 0$ & $100 \pm 0$ & $\begin{array}{l}\text { per minute } \\
197 \pm 13\end{array}$ \\
\hline \multicolumn{9}{|c|}{ Ether started } \\
\hline $\begin{array}{l}2 \\
3 \\
4 \\
5\end{array}$ & $\begin{array}{l}99 \pm 6 \\
99 \pm 3 \\
90 \pm 4 \\
93 \pm 5\end{array}$ & $\begin{array}{l}42 \pm 4 \\
39 \pm 4 \\
32 \pm 4 \\
38 \pm 6\end{array}$ & $\begin{array}{l}58 \pm 6 \\
56 \pm 4 \\
50 \pm 3 \\
54 \pm 4\end{array}$ & $\begin{array}{l}-3.4 \pm 0.6 \\
-3.3 \pm 0.4 \\
-2.9 \pm 0.4 \\
-2.6 \pm 0.4\end{array}$ & $\begin{array}{l}90 \pm 8 \\
90 \pm 5 \\
83 \pm 9 \\
86 \pm 5\end{array}$ & $\begin{array}{l}98 \pm 7 \\
97 \pm 3 \\
84 \pm 5 \\
86 \pm 6\end{array}$ & $\begin{array}{c}100 \pm 3 \\
96 \pm 7 \\
77 \pm 8 \\
79 \pm 10\end{array}$ & $\begin{array}{l}195 \pm 15 \\
198 \pm 15 \\
194 \pm 20 \\
212 \pm 21\end{array}$ \\
\hline \multicolumn{9}{|c|}{ Ether stopped } \\
\hline $\begin{array}{r}6 \\
7 \\
8 \\
9 \\
10\end{array}$ & $\begin{array}{l}76 \pm 4 \\
92 \pm 12 \\
75 \pm 8 \\
82 \pm 9 \\
73 \pm 8\end{array}$ & $\begin{array}{l}32 \pm 2 \\
34 \pm 7 \\
28 \pm 3 \\
26 \pm 3 \\
29 \pm 4\end{array}$ & $\begin{array}{l}40 \pm 3 \\
50 \pm 7 \\
40 \pm 3 \\
40 \pm 2 \\
43 \pm 5\end{array}$ & $\begin{array}{l}-1.8 \pm 0.5 \\
-2.2 \pm 0.6 \\
-2.6 \pm 0.7 \\
-3.4 \pm 0.3 \\
-3.2 \pm 0.4\end{array}$ & $\begin{array}{l}68 \pm 8 \\
94 \pm 13 \\
85 \pm 9 \\
92 \pm 8 \\
78 \pm 9\end{array}$ & $\begin{array}{l}69 \pm 7 \\
94 \pm 14 \\
79 \pm 6 \\
82 \pm 6 \\
95 \pm 8\end{array}$ & $\begin{array}{l}67 \pm 17 \\
69 \pm 16 \\
60 \pm 12 \\
87 \pm 9 \\
71 \pm 7\end{array}$ & $\begin{array}{l}208 \pm 32 \\
210 \pm 27 \\
142 \pm 18 \\
183 \pm 39\end{array}$ \\
\hline
\end{tabular}




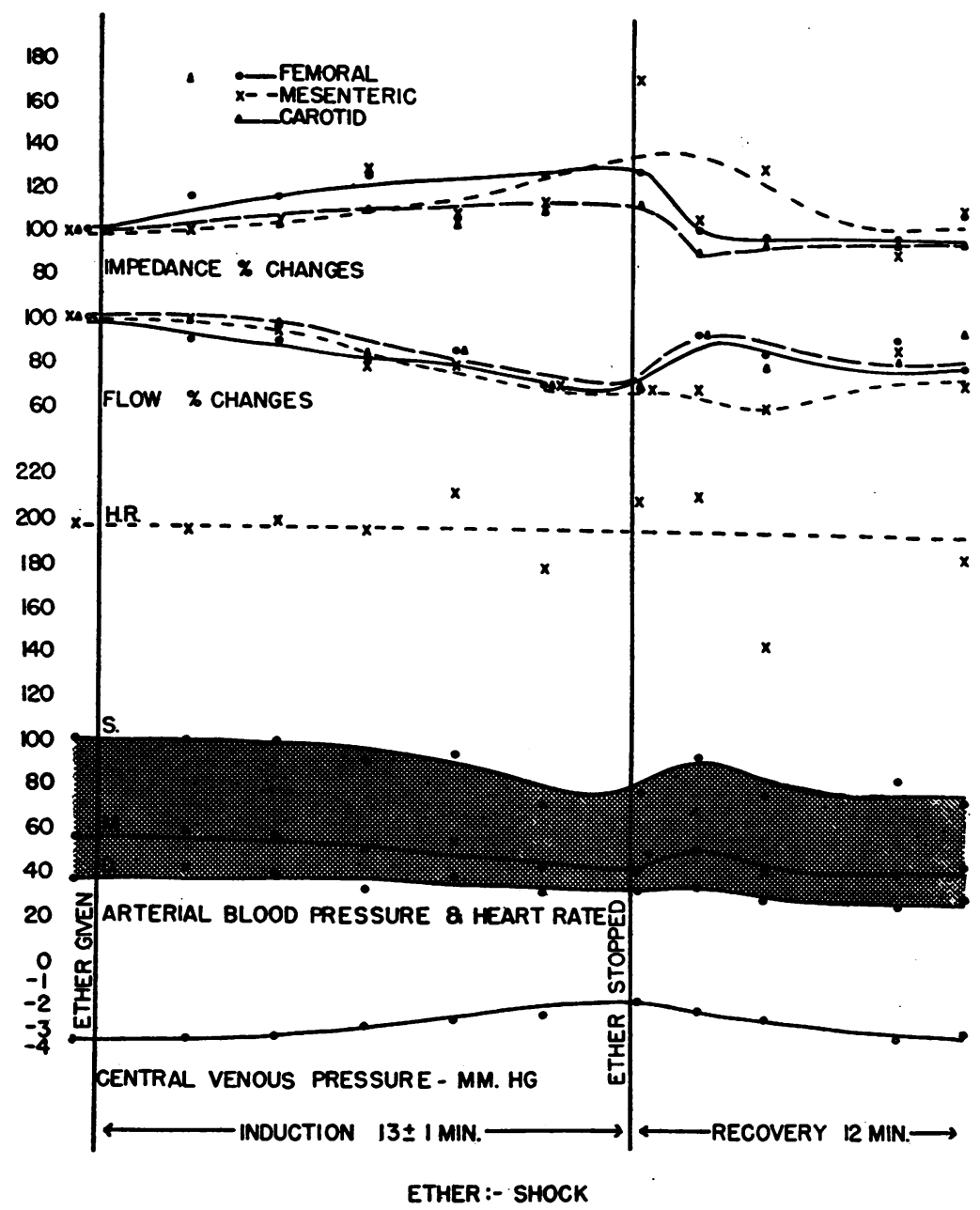

Fig. 5. Pressure, Flow, and Impedance Changes in Dogs in Shock When Carried from Light Ether Anesthesia to a Deep Level by AdMINISTRATION OF ETHER

Layout and interpretation of chart as for Figure 4 (see Table IV). The series of points immediately before "ether stopped" is omitted from Table IV.

carotid vascular beds tended to decrease immediately after removing the ether, and then to rise again towards original levels. The mesenteric impedance, conversely, tended to rise while the others fell, and then to fall again towards the starting value.

In shock (Table IV, Figure 5), the effects of deepening the anesthesia were comparable to the preceding except that: The rise in central venous pressure was usually not as high as previously. The initial rise in arterial pressure was usually lacking and the subsequent fall was of greater magnitude than before, with a considerable decrease in pulse pressure (Figure 5).
In shock, the sequence in recovery of a light level of anesthesia was almost the same as in good condition, except that events were drawn out a little in time. The heart rate showed no consistent or significant changes with administration of ether or recovery from it. Charts of trends of pressure and flow are shown in Figures 4 and 5 , and actual records of changes with varying depth of ether in Figure 6. Individual variations were considerable. In some of our runs, the initial rise in blood pressure was absent (Figure 6A). Similarly, the reciprocal flow changes in carotid and femoral arteries on the one hand and mesenteric vein flow on the other, 

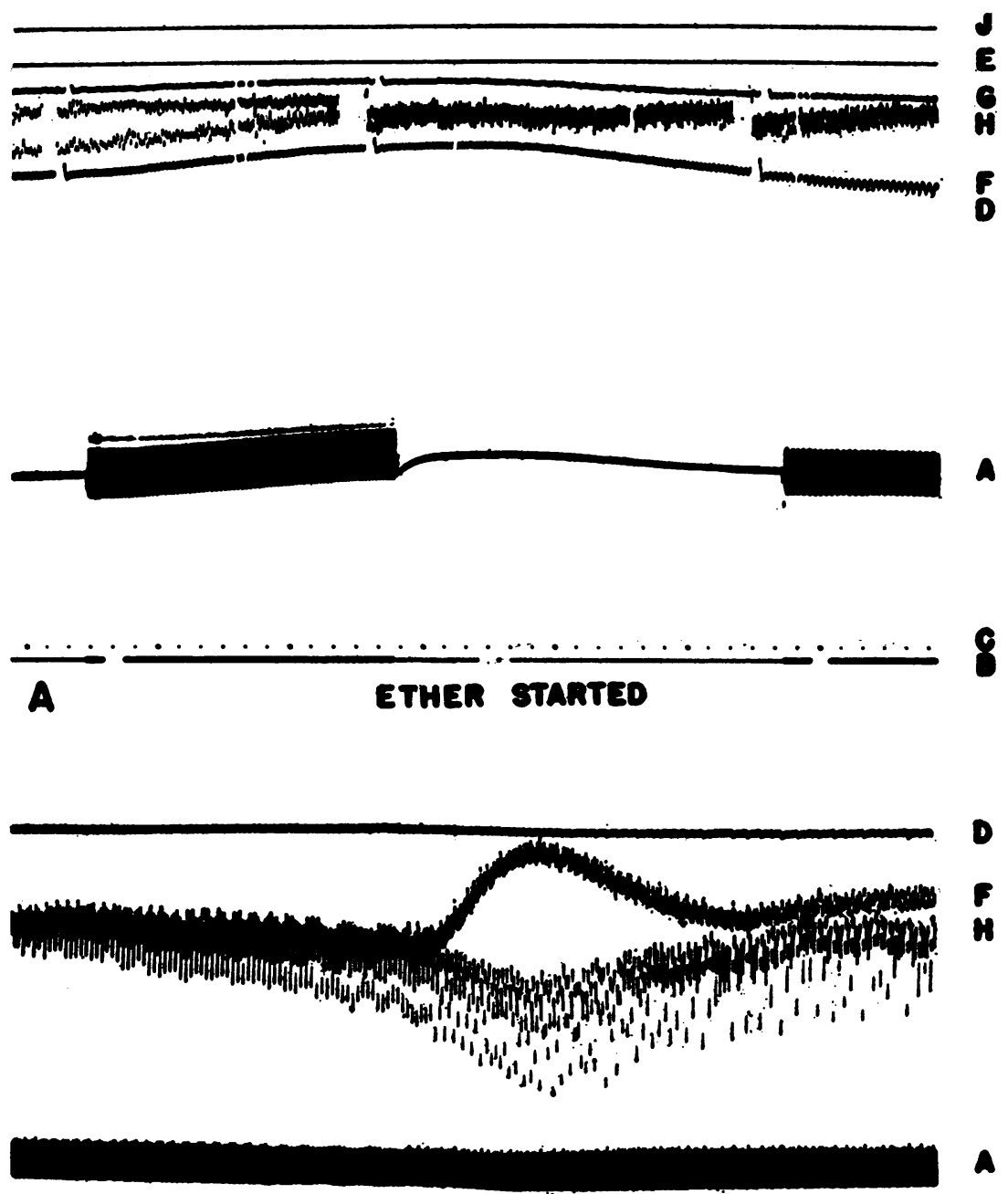

\section{ETHER STOPPED}

Fig. 6. A. Pressure and Flow Changes Before and After Administering ETHER (COMPare with MEANS IN TABLE III)

The first part of the record is taken while the animal is becoming lighter from a previous deepening with ether. Trends in flows and arterial pressures are upwards, and in venous pressure, downwards. With the start of ether administration, a downward trend in flows and arterial pressure appears and venous pressure starts to rise. In this case, the arterial pressure does not show an initial rise early in the course of deepening, as many of our animals do, and as shown in Figure 5.

\section{B. Characteristic flow and Pressure Changes After Stopping Ether}

After turning off the ether, a downward trend in arterial pressure is reversed, and a rising venous pressure starts to fall. Mesenteric vein flow shows evidence of a brief episode of vasoconstriction, and the femoral artery flow, a simultaneous phase of vasodilation, followed by a trend towards original levels. Key to tracings are as given in Figure 3. 


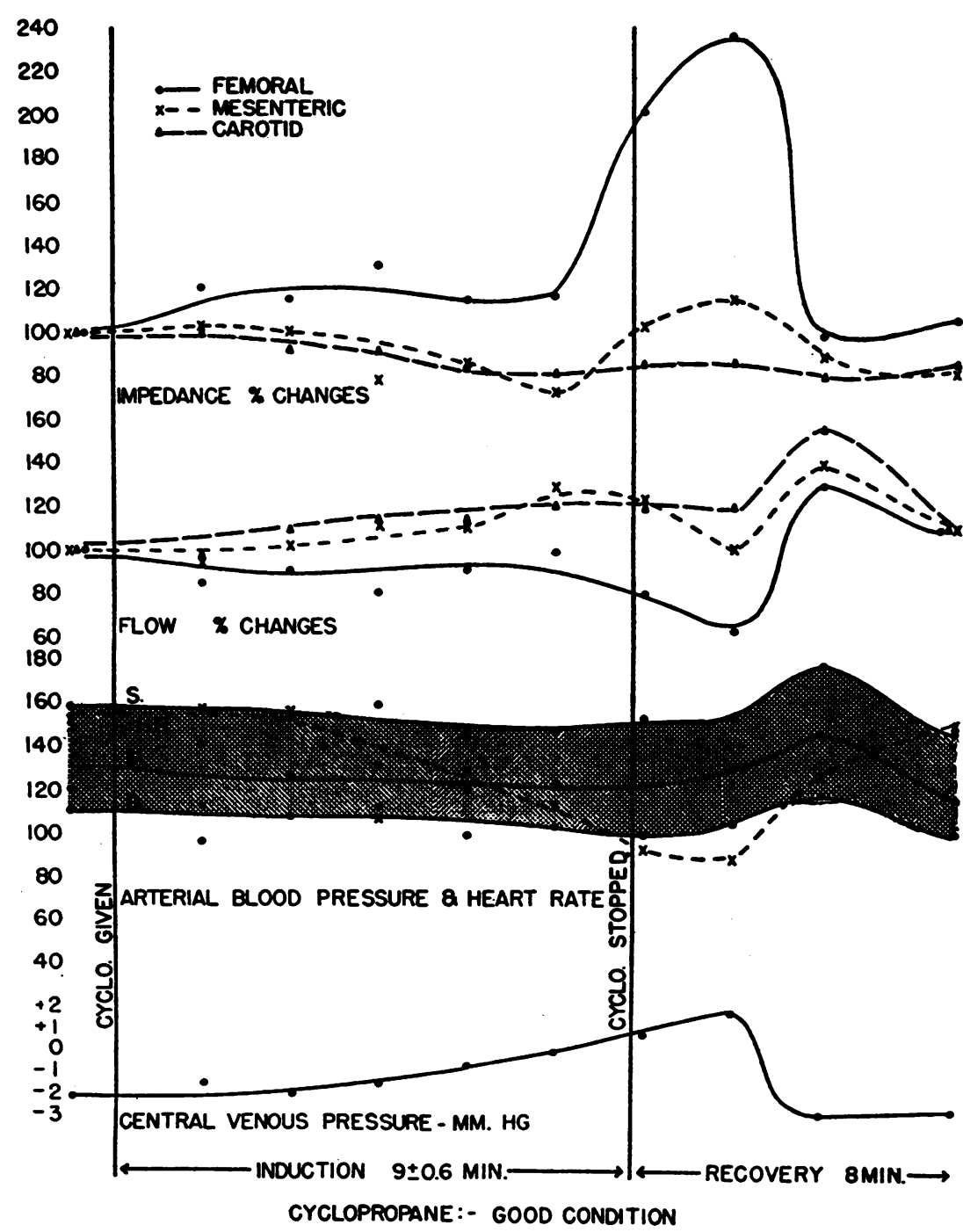

Fig. 7. Pressure, Flow, and Impedance Changes in Dogs in Good Condition Under Cyclopropane Anesthesia, When Carried from a Control Point Under Very Light Cyclopropane Anesthesia to a Deep level Close to RESPIRATORY FAILURE

Abscissa and general considerations are as for Figure 4 (see Table V).

found usually after removing the ether, were sometimes absent entirely, with all three flows recovering steadily and at about the same rate.

Episodes of deliberate deepening of ether anesthesia to a point near respiratory failure seemed to be deleterious, as flows and pressures seldom recovered to original levels (see Figures 4 and 5). Several such episodes of deepening sometimes sufficed to put the animal into a shock-like state, even without any considerable blood loss. This was in contrast to the behavior of the animal under cyclopropane and is in agreement with the observations of Evans and Beecher (12) who found that dogs under ether tolerated shocking procedures less well than dogs under cyclopropane.

Progressive changes with shock. With a light level of ether anesthesia as shock progressed, the systolic, diastolic, and mean arterial pressures declined. The pulse pressure was initially much wider under ether than under cyclopropane or under evipal (Figures 11, 12), and as shock 
progressed, the pulse pressure became narrower than it had been. In this case (cf. evipal), the systolic pressure fell more rapidly than diastolic. This process continued until death.

\section{Cyclopropane}

Variation in anesthesia depth. Flow and pressure records of dogs in good condition under cyclopropane anesthesia, taken at a control level

TABLE V

Cyclopropane-dog in good condition

Means with standard errors

\begin{tabular}{|c|c|c|c|c|c|c|c|c|}
\hline & \multicolumn{3}{|c|}{ Arterial blood pressure } & \multirow[b]{2}{*}{ Venous pressure } & \multicolumn{3}{|c|}{ Flows in percentages of control level } & \multirow[b]{2}{*}{ Heart rate } \\
\hline & Systolic & Diastolic & Mean & & $\begin{array}{c}\text { Femoral } \\
\text { artery }\end{array}$ & $\begin{array}{l}\text { Carotid } \\
\text { artery }\end{array}$ & $\begin{array}{c}\text { Superior } \\
\text { mesenteric } \\
\text { or portal vein }\end{array}$ & \\
\hline $\begin{array}{l}\text { Control } \\
\text { Point } 1\end{array}$ & $159 \pm 5$ & $\begin{array}{c}m m \cdot H g \\
111 \pm 5\end{array}$ & $121 \pm 6$ & $\begin{array}{c}m m \cdot \mathrm{Hg} \\
-2.2 \pm 0.3\end{array}$ & $100 \pm 0$ & $100 \pm 0$ & $100 \pm 0$ & $\begin{array}{c}\text { per minute } \\
153 \pm 8\end{array}$ \\
\hline \multicolumn{9}{|c|}{ Cyclopropane started } \\
\hline $\begin{array}{l}2 \\
3 \\
4 \\
5 \\
6\end{array}$ & $\begin{array}{l}141 \pm 14 \\
153 \pm 5 \\
159 \pm 9 \\
145 \pm 7 \\
147 \pm 6\end{array}$ & $\begin{array}{c}97 \pm 12 \\
108 \pm 5 \\
112 \pm 8 \\
99 \pm 6 \\
103 \pm 6\end{array}$ & $\begin{array}{l}113 \pm 13 \\
127 \pm 5 \\
131 \pm 9 \\
120 \pm 6 \\
123 \pm 7\end{array}$ & $\begin{array}{l}-1.6 \pm 0.5 \\
-2.04 \pm 0.3 \\
-1.6 \pm 0.5 \\
-0.7 \pm 0.4 \\
-0.1 \pm 0.4\end{array}$ & $\begin{array}{l}85 \pm 8 \\
91 \pm 5 \\
81 \pm 8 \\
91 \pm 6 \\
99 \pm 13\end{array}$ & $\begin{array}{r}98 \pm 4 \\
109 \pm 3 \\
114 \pm 9 \\
114 \pm 6 \\
120 \pm 8\end{array}$ & $\begin{array}{r}96 \pm 7 \\
102 \pm 5 \\
112 \pm 8 \\
112 \pm 7 \\
129 \pm 7\end{array}$ & $\begin{array}{l}157 \pm 13 \\
157 \pm 7 \\
107 \pm 14 \\
129 \pm 10 \\
113 \pm 9\end{array}$ \\
\hline \multicolumn{9}{|c|}{ Cyclopropane stopped } \\
\hline $\begin{array}{r}7 \\
8 \\
9 \\
10\end{array}$ & $\begin{array}{l}153 \pm 12 \\
153 \pm 8 \\
177 \pm 11 \\
146 \pm 6\end{array}$ & $\begin{array}{l}99 \pm 10 \\
104 \pm 7 \\
118 \pm 7 \\
100 \pm 6\end{array}$ & $\begin{array}{l}122 \pm 10 \\
130 \pm 5 \\
146 \pm 7 \\
116 \pm 6\end{array}$ & $\begin{array}{l}+0.7 \pm 0.7 \\
+1.7 \pm 0.5 \\
-3.0 \pm 0.4 \\
-2.8 \pm 0.3\end{array}$ & $\begin{array}{l}80 \pm 15 \\
63 \pm 9 \\
129 \pm 12 \\
108 \pm 9\end{array}$ & $\begin{array}{l}119 \pm 9 \\
119 \pm 7 \\
154 \pm 9 \\
108 \pm 4\end{array}$ & $\begin{array}{l}123 \pm 31 \\
101 \pm 11 \\
138 \pm 11 \\
109 \pm 4\end{array}$ & $\begin{array}{c}93 \pm 8 \\
89 \pm 5 \\
127 \pm 9 \\
150 \pm 10\end{array}$ \\
\hline
\end{tabular}

TABLE VI

Cyclopropane-dog in shock

Means with standard errors

\begin{tabular}{|c|c|c|c|c|c|c|c|c|}
\hline & \multicolumn{3}{|c|}{ Arterial blood pressure } & \multirow[b]{2}{*}{ Venous pressure } & \multicolumn{3}{|c|}{ Flows in percentages of control level } & \multirow[b]{2}{*}{ Heart rate } \\
\hline & Systelic & Diastolic & Mean & & $\begin{array}{l}\text { Femoral } \\
\text { artery }\end{array}$ & $\begin{array}{l}\text { Carotid } \\
\text { artery }\end{array}$ & $\begin{array}{c}\text { Superior } \\
\text { mesenteric } \\
\text { or portal vein }\end{array}$ & \\
\hline $\begin{array}{l}\text { Control } \\
\text { Point } 1\end{array}$ & $85 \pm 2$ & $\begin{array}{c}m m \cdot B g \\
39 \pm 2\end{array}$ & $52 \pm 2$ & $\begin{array}{c}m m . \mathrm{Hg}_{\mathrm{g}} \\
-3.6 \pm 0.4\end{array}$ & $100 \pm 0$ & $100 \pm 0$ & $100 \pm 0$ & $\begin{array}{c}\text { per minute } \\
168 \pm 9\end{array}$ \\
\hline
\end{tabular}

Cyclopropane started

\begin{tabular}{|c|c|c|c|c|c|c|c|c|}
\hline $\begin{array}{l}2 \\
3 \\
4 \\
5 \\
6 \\
7\end{array}$ & $\begin{array}{l}94 \pm 5 \\
91 \pm 4 \\
79 \pm 4 \\
75 \pm 4 \\
85 \pm 6 \\
80 \pm 5\end{array}$ & $\begin{array}{l}42 \pm 2 \\
41 \pm 5 \\
40 \pm 3 \\
33 \pm 3 \\
42 \pm 5 \\
39 \pm 4\end{array}$ & $\begin{array}{l}58 \pm 3 \\
55 \pm 3 \\
53 \pm 3 \\
46 \pm 4 \\
56 \pm 5 \\
51 \pm 4\end{array}$ & $\begin{array}{l}-3.6 \pm 0.4 \\
-2.8 \pm 0.4 \\
-3.4 \pm 0.4 \\
-2.1 \pm 0.4 \\
-2.8 \pm 0.5 \\
-2.2 \pm 0.3\end{array}$ & $\begin{array}{l}97 \pm 8 \\
91 \pm 8 \\
94 \pm 16 \\
90 \pm 9 \\
86 \pm 11 \\
75 \pm 12\end{array}$ & $\begin{array}{c}106 \pm 8 \\
105 \pm 6 \\
105 \pm 7 \\
94 \pm 8 \\
109 \pm 10 \\
97 \pm 9\end{array}$ & $\begin{array}{c}103 \pm 5 \\
106 \pm 5 \\
100 \pm 15 \\
88 \pm 9 \\
111 \pm 20 \\
87 \pm 13\end{array}$ & $\begin{array}{l}168 \pm 14 \\
181 \pm 10 \\
156 \pm 9 \\
163 \pm 15 \\
128 \pm 7 \\
143 \pm 10\end{array}$ \\
\hline \multicolumn{9}{|c|}{ Cyclopropane stopped } \\
\hline $\begin{array}{r}8 \\
9 \\
10 \\
11\end{array}$ & $\begin{array}{l}68 \pm 4 \\
74 \pm 8 \\
79 \pm 5 \\
77 \pm 4\end{array}$ & $\begin{array}{l}29 \pm 3 \\
38 \pm 6 \\
36 \pm 3 \\
31 \pm 3\end{array}$ & $\begin{array}{l}41 \pm 4 \\
51 \pm 5 \\
50 \pm 3 \\
46 \pm 3\end{array}$ & $\begin{array}{l}-2.0 \pm 0.9 \\
-1.4 \pm 0.4 \\
-3.0 \pm 0.7 \\
-3.5 \pm 0.4\end{array}$ & $\begin{array}{l}72 \pm 13 \\
66 \pm 11 \\
99 \pm 16 \\
87 \pm 9\end{array}$ & $\begin{array}{c}72 \pm 11 \\
84 \pm 10 \\
108 \pm 12 \\
96 \pm 7\end{array}$ & $\begin{array}{r}80 \pm 19 \\
78 \pm 13 \\
106 \pm 13 \\
107 \pm 18\end{array}$ & $\begin{array}{l}116 \pm 10 \\
122 \pm 9 \\
154 \pm 12 \\
172 \pm 17\end{array}$ \\
\hline
\end{tabular}




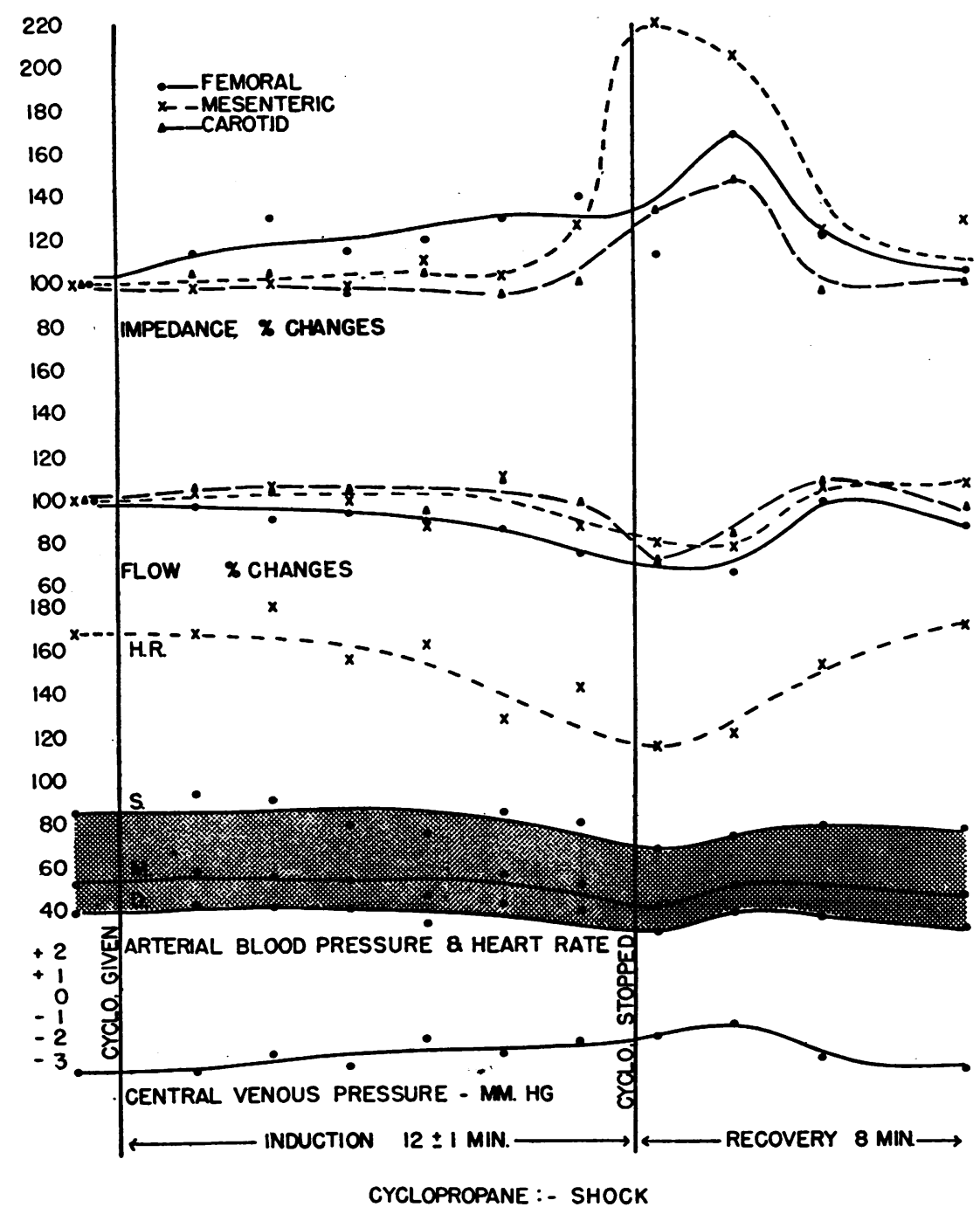

Fig. 8. Pressure, Flow, and Impedance Changes in Dogs in Shock When Carried from Very light Cyclopropane Anesthesia to a Very Deep level (SEE TABLE vI)

of very light anesthesia and then followed through a process of deepening with cyclopropane to a point approaching respiratory failure, in a manner similar to that described for ether, showed the following changes (Table V, Figure 7): Central venous pressure rose remarkably and progressively, reaching levels far above those attained under ether or evipal. Arterial pressure was either unaffected or showed inconstant changes. Heart rate progressively decreased. Femoral flow tended to decrease, while flow in carotid and mesenteric beds increased. Hydraulic impedance in the femoral bed usually increased and, in the carotid and mesenteric, generally decreased. The lack of a constant effect on arterial blood pressure is in agreement with Waters (13). A slowing of the heart rate under cyclopropane has often been reported previously (see Seevers and Waters (14)). In studying the effects of cyclopropane on the circulation in a heart-lung preparation (dogs), Krayer and Beecher (15) observed a striking rise in venous pressure under this agent. Volpitto, Woodbury, and Hamilton (16) reported a rise in venous pressure in man under cyclopropane. 


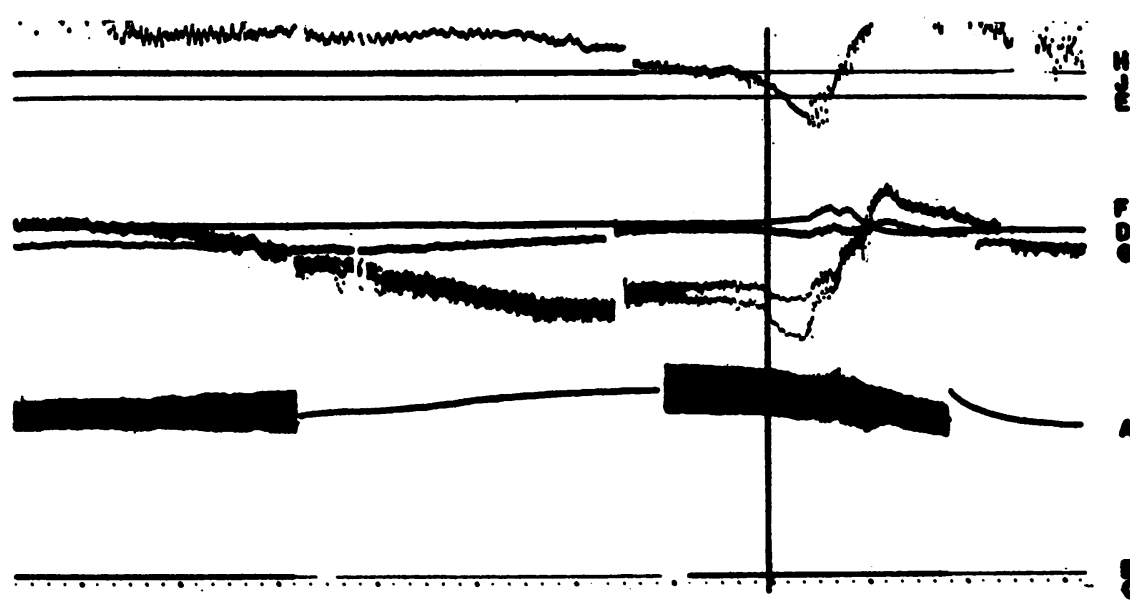

orolo. stopreo

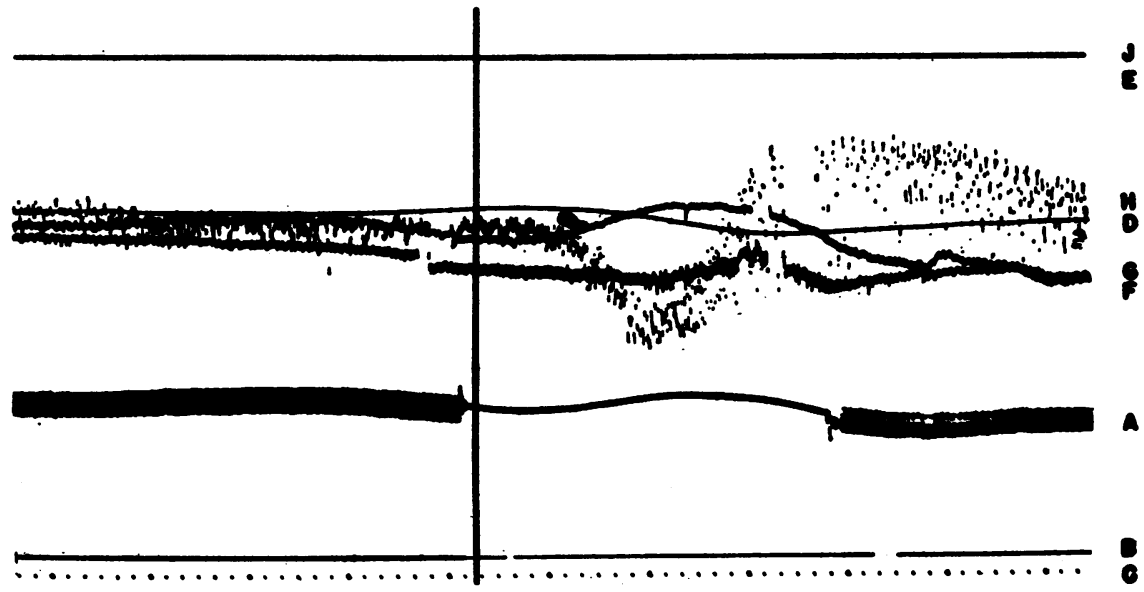

crola stOPPEO

Fig. 9. Pressure and Flow Changes After Administration of Cyclopropane had Already Been Started

The 2 records show the later phases of deepening anesthesia with cyclopropane, the time of stopping the administration, and the recovery. The upper record shows a typical decrease in femoral flow, increase in carotid flow, rise in venous pressure, and slowing of heart rate on deepening anesthesia, with characteristic rebound in femoral and mesenteric flow on recovery. The marked rise in arterial pressure with deepening is atypical, and the decrease in mesenteric flow in deep anesthesia is greater than usual. The lower record shows typical rising venous pressure and constant arterial pressure on deepening, with the typical rise and fall of arterial pressure on recovery. Femoral flow changes are less marked than usual.

Upon removal of cyclopropane and on allowing the animal to recover, a rather complex series of changes characteristically occurred, as follows: The elevated central venous pressure fell rapidly to a point slightly below its original value and gradually rose to a normal level for light anesthesia. The arterial pressure sometimes fell briefly but usually approached the original condition only after a sharp rise above its final value, described previously by Brace, Scherf, and Spire (17). Heart rate was restored rapidly to normal. Femoral flow decreased sharply for a short time and then showed a phase of increase from which it diminished to a stable value. Carotid artery flow showed a less marked transient wave of increased flow, after which it fell slowly to normal. Mesenteric vein flow usually showed changes similar to those of the 

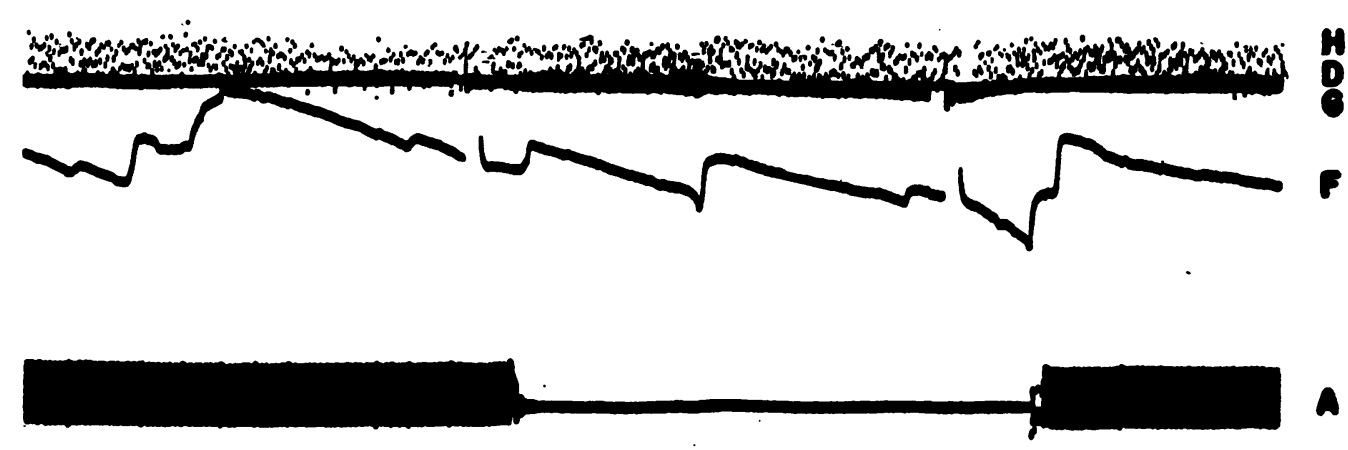

Q

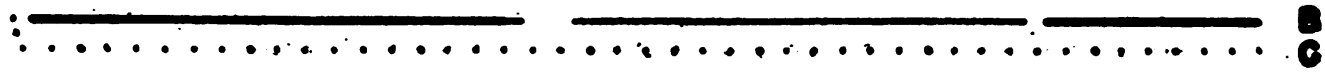

Fig. 10. Optical Tracings of a Dog Under Ether Anesthesia Taken at a Tmme When Flow in the Femoral Artery Was Showing Irregular and Unpredictable Changes, Without Evidence of Compensating Flow Changes in Carotid or Mesenteric Vascular Bed, or of Corresponding Changes in Central Arterial or Central Venous Pressure

femoral, but with smaller excursions. Hydraulic impedances showed an increase followed by a decrease, a phenomenon most marked in the femoral vascular bed, less marked in the mesenteric, and questionably present in the carotid.

The rise in central venous pressure, the fall in heart rate, and the increase in carotid and mesenteric flow and the depression of femoral flow during deepening anesthesia were quite constant. Arterial pressure changes during deepening were variable; sometimes no change appeared. More of ten there were unpredictable phases of increased or decreased pressure.

On recovery, the fall in venous pressure was always present, but the arterial pressure sometimes fell steadily (Figure 9A) or rose and then fell (Figures 7,9B), or changed very little. The changes in flow early in recovery were quite variable in degree; examples of some variations met are shown in Figure 9. The time relationship which the flow and pressure changes bore to each other on recovery were also quite variable. Thus, the phase of vasodilatation, characterized by the increase in femoral and mesenteric flow, occurred in some cases while the pressure was falling, as in Figure 9A, or partly during a phase of rising pressure and partly during a phase of fall, as in 9B, or entirely during a rise. Similarly, flow changes in one vascular bed were not necessarily accompanied by parallel changes in another, as in Figure 9B, where the carotid flow changes were entirely out of phase with the mesenteric and femoral.

In shock, the changes on deepening the anesthesia (Table VI, Figure 8) were comparable to those found in the animal in good condition, except that: The central venous pressure started lower and did not rise to the same high level as formerly. The arterial blood pressure was usually somewhat depressed when the anesthetic was pushed to a deep level. The heart rate was a little faster throughout than it had been during good condition. As formerly, slowing occurred with deepening anesthesia. The flow changes were directionally the same, but showed less violent swings on recovery and the phases were somewhat prolonged.

These episodes of deepening with cyclopropane, in contrast to those with ether, appeared to have no particularly lasting deleterious effects on the dogs. Flows and pressures usually returned to control levels upon recovery from deepening, 


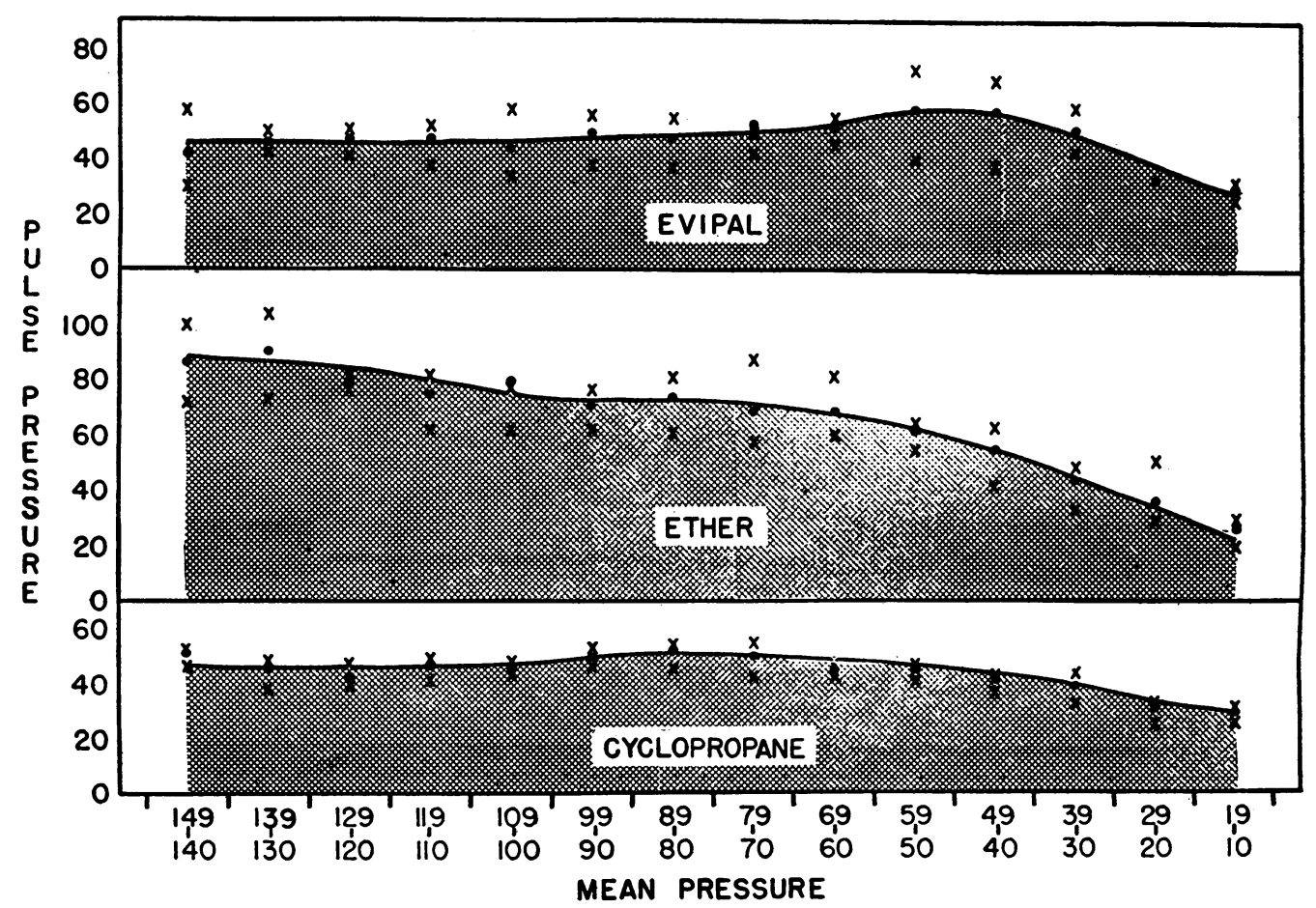

Fig. 11. Pulse Pressure Changes With Shock Under Evipal, Ether, and Cyclopropane The dots represent the averages of all readings within the mean arterial pressure range shown on the abscissa. The crosses denote the limits between which half of our pulse pressure readings lie, and hence give an indication of the scatter.

and in many dogs, episodes of deepening were imposed 5 or 6 times without any noticeable deterioration of the circulation of the animal.

Progressive changes with shock. With a light level of cyclopropane anesthesia, as shock progressed, the systolic, diastolic, and mean pressures declined. The pulse pressure was initially narrow, as under evipal, and remained fairly constant throughout the shock process (Figures $11,12)$, with the exception that occasionally an animal showed some widening of the pulse pressure as the mean blood pressure approached the shock level; but in these cases, as the shock progressed, this would narrow again to approximately the original size.

\section{GENERAL CONSIDERATIONS}

The optical tracings (Figure 12) show an example of a further difference in the nature of the pulse wave with the 3 anesthetics. With animals in good condition under ether, the mean pressure is well below a point halfway between systolic and diastolic pressure. Under evipal and cyclopropane, the mean pressure is nearer the midpoint between the systolic and diastolic peaks.

The data obtained (Table VII) give no evidence of different flow values under ether and cyclopropane, respectively, in these 3 vascular beds; accordingly, one is tempted to surmise that the cardiac output under these 2 agents might be likewise comparable, and in fact, Blalock (18) and Robbins and Baxter (19) have shown respectively that the cardiac output is greatly increased both under ether and under cyclopropane. If this speculation be valid, one can couple it with the lower heart rate under light cyclopropane than under light ether and conclude that the difference in pulse pressure observed is, in all likelihood, due to differences in the elastic properties of the aorta and large arteries with these 2 agents. This would mean that the hydraulic capacitance ${ }^{4}$ of the aorta and large

${ }^{4}$ Hydraulic capacitance refers to distensibility, in a sense comparable to electrostatic capacitance, and not to volume. 
arteries is greater under cyclopropane than under ether. In other words, the elastic tension or Hooke's law constant of the aorta should, if this view holds, be greater under ether than under cyclopropane and it would appear to serve as a more effective damping device under cyclopropane than under ether. It is possible that differences in the time of systolic upswing might in part impair the validity of these speculations.

Rhythmic sinusoidal fluctuations in arterial blood pressure (Traube-Hering waves) were completely absent in all 25 of our dogs under ether anesthesia. They were present in 5 of 11 dogs under cyclopropane and in 14 out of 27 dogs under evipal. Although present in about half the dogs under evipal and cyclopropane, Traube-Hering waves were most persistent and of greater amplitude under evipal than under cyclopropane. If such waves were present at the time of injection of evipal intravenously, they invariably disappeared with the other acute effects of the injection, of ten to reappear gradually with recovery after 8 or 10 minutes.

Our records of mean central venous pressure showed in most cases a tendency towards progressive decline during the shock process, with a terminal rise. This fall in central venous pressure generally observed is at variance with the findings reported by Werle, Cosby, and Wiggers (3), who, however, did not measure the mean central venous pressure, but took their value from an arbitrary point on the venous pulse curve. The progressive venous pressure decline could be interrupted or reversed temporarily by deepening the anesthesia by administration of ether, cyclopropane, or evipal. Apart from the varying duration of the effects of deepening anesthesia with various agents, the decline of central venous pressure with shock occurred under all 3 of these substances.

The nature of the agonal changes in animals dying in hemorrhagic shock differed according to the anesthetic used. Under cyclopropane or ether, the dying animals usually showed a progressive decline in systolic peak pressures with slowing of the heart rate until complete circulatory standstill was achieved. In contrast, animals dying of shock under evipal showed a similar initial slowing of the pulse and fall in pressure, followed characteristically by a brief burst of cardiac recovery, with restoration of blood flow and transient fall in central venous pressure. The recovery might last for 1 or 2 minutes and then fade out with resulting final cardiac standstill, or, in some instances, regress only to flare up again. The cardiac slowing before the reactivation observed under evipal was in some dogs not marked, but in about half (12 out of 26) of our animals under evipal, the heart slowed to complete standstill for a period of from 10 seconds to a minute, and then recovered as described for a minute or two. Such "recoveries" were not observed under ether or under cyclopropane.

When arterial and central venous pressures were measured carefully from the same zero base-line at the level of the opening of the vena cava, as explained previously, even in an animal dead from hemorrhagic shock, the arterial pres-

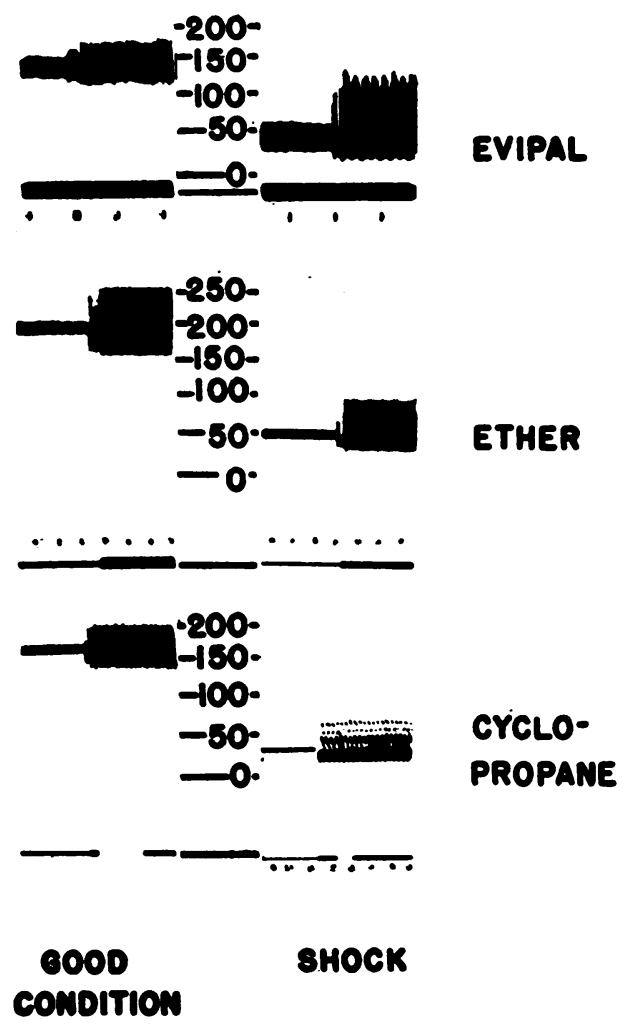

Fig. 12. Optical Arterial Blood Pressure, Mean and Full Pulse Pressures With the Animal in Good Condition and in Shock, Under Evipal, Ether, aNd Cyclopropane

Each pair shows records from the same animal, taken at different times during an experiment. 
TABLE VII

Tabulation of body surface of dogs, and flows and impedances, corrected for body surface, in dogs under light cyclopropane and under light ether anesthesia, in good condition and shock

\begin{tabular}{|c|c|c|c|c|c|c|}
\hline$\underset{\text { Burface }}{\text { Body }}$ & $\begin{array}{c}\text { Femoral } \\
\text { flow }\end{array}$ & $\begin{array}{c}\text { Carotid } \\
\text { flow }\end{array}$ & $\begin{array}{l}\text { Mesenteric } \\
\text { flow }\end{array}$ & $\begin{array}{c}\text { Femoral } \\
\text { impedance }\end{array}$ & $\begin{array}{c}\text { Carotid } \\
\text { impedance }\end{array}$ & $\begin{array}{l}\text { Mesenteric } \\
\text { impedance }\end{array}$ \\
\hline sq. $m$. & $\begin{array}{l}c c \text { per second } \\
\text { per sq. } m .\end{array}$ & $\begin{array}{c}c c \text { per second } \\
\text { per sq. } m .\end{array}$ & $\begin{array}{c}c c \text {. per second } \\
\text { per sq. } m \text {. }\end{array}$ & & & \\
\hline \multicolumn{7}{|c|}{ Cyclopropane- dog in good condition } \\
\hline $0.66 \pm 0.02$ & $0.43 \pm 0.18$ & $1.4 \pm 0.3$ & $4.4 \pm 0.6$ & $630 \pm 150$ & $130 \pm 15$ & $38 \pm 9$ \\
\hline \multicolumn{7}{|c|}{ Ether-dog in good condition } \\
\hline $0.73 \pm 0.02$ & $0.37 \pm 0.08$ & $1.3 \pm 0.2$ & $3.5 \pm 1.0$ & $460 \pm 230$ & $120 \pm 40$ & $39 \pm 7$ \\
\hline \multicolumn{7}{|c|}{ Cyclopropane-dog in shock } \\
\hline $0.68 \pm 0.02$ & $0.20 \pm 0.07$ & $0.51 \pm 0.01$ & $1.8 \pm 0.3$ & $520 \pm 110$ & $130 \pm 25$ & $36 \pm 7$ \\
\hline \multicolumn{7}{|c|}{ Ether-dog in shock } \\
\hline $0.70 \pm 0.03$ & $0.29 \pm 0.08$ & $0.66 \pm 0.08$ & $1.8 \pm 0.3$ & $420 \pm 200$ & $96 \pm 12$ & $47 \pm 8$ \\
\hline
\end{tabular}

sure never fell to zero, but came to rest with the venous pressure at 2 to $5 \mathrm{~mm}$. $\mathrm{Hg}$ above the zero level mentioned. No significant differences in heart rate changes between the 3 anesthetic agents were observed as shock progressed.

As one can readily see from the flow changes recorded in Figures 6 and 9, femoral, carotid, and mesenteric flows may not behave alike when all 3 are recorded simultaneously. Certain differences in the reactions of the femoral flow from those of the carotid and mesenteric show likewise in the chart of the averages under cyclopropane in animals in good shape (Figure 7). It is further apparent from the records that there is no consistent correlation of vasoconstriction or vasodilatation in any of these 3 vascular beds with changes in arterial blood pressure or in central venous pressure.

Spontaneous changes of considerable magnitude have been recorded in one or another of these vessels, without any evidence of compensatory changes in the other beds, or any repercussions in systemic pressure. An example of such changes is seen in Figure 10, where femoral flow shows considerable spontaneous and totally irregular flow changes without any sign of corresponding fluctuations in carotid or mesenteric flows or in pressures. Regular phasic flow changes of a similar nature have been recorded.
In our experience, such phasic or irregular flow changes have been met with most frequently in the femoral artery. The flow in the carotid and mesenteric vessels has appeared to be more stable. These effects have been observed under all 3 of the anesthetic agents.

Insofar as the primary anesthetic effects go, the 3 agents considered here have great clinical value, notwithstanding considerable variation in their particular fields of usefulness. Pertinent to the problem of determining the best anesthetic to use in men in shock is a comparison of the secondary effects of these agents, particularly on the circulation. In this connection, several facts stand out; for example, our findings suggest that cyclopropane is tolerated better by dogs in shock than is ether or evipal. This confirms the previous observation of Evans and Beecher (12). It may in part be due to the observed fact that the carotid and mesenteric flows and the arterial pressure were preserved well even when the cyclopropane was pushed to a deep level of anesthesia. This was true with cyclopropane in animals in shock as well as in good condition; but was not the case with ether or evipal. From this, one might generalize that cyclopropane affords a greater margin of safety with respect to blood pressure and blood flow preservation in essential vascular beds than do the other 2 
agents. These findings in dogs suggest the desirability of searching for a similar relationship in man. The significance of the extraordinary rise of venous pressure under cyclopropane is not clear from our experiments, and should be studied further. In evaluating cyclopropane for use in wounded men, one must not lose sight of a factor not included in the present study, namely, the well-recognized tendency of cyclopropane to sensitize the heart to stimuli which produce ventricular fibrillation. This accounts for a disturbing number of clinical deaths.

As well recognized clinically and as shown in this and other experimental studies, anesthesia may be deleterious in shock. Since this is the case, the briefer the period of anesthesia, the better it is for the patient; accordingly, the rapid induction of cyclopropane anesthesia and the swift recovery from it offer a considerable advantage over ether, in this respect.

Under evipal, the tendency of the central venous pressure to rise, and the usual failure of arterial blood pressure and flow to return to original values after fairly small injections of evipal, support the view that this agent had best be reserved for brief anesthesia in subjects in good condition.

\section{SUMMARY}

The effect on the circulation of 3 representative anesthetic agents has been studied in dogs with the purpose of obtaining objective information as to the best choice of anesthetic agent for use in seriously wounded men. The influence of varying depths of anesthesia on heart rate, on systolic, diastolic, and mean arterial blood pressure, on central venous pressure, and on blood flow in 3 vascular beds, femoral, carotid, and mesenteric, has been studied in dogs in good condition and in shock (hemorrhage).

Sodium evipal effects were as follows: Deepening the anesthesia of subjects in good condition and in shock was followed in both instances by reduction in systolic, diastolic, and mean arterial pressures, by rise in central venous pressure, by diminution in flow through the carotid, femoral, and mesenteric vascular beds. There were no consistent changes in heart rate. The maximum effect on the circulation usually occurred about a minute after the intravenous injection. All components thereafter gradually approached their original levels; but when shock was present, the recovery process was slower than formerly and the original levels were not usually attained.

Under evipal, as shock progressed, diastolic blood pressure fell faster than systolic, giving a pulse pressure which widened progressively until the terminal stages.

Ether effects were as follows: With the subjects in good condition, deepening of the anesthesia was associated with a progressive rise in venous pressure; a slight initial rise in systolic, diastolic, and mean arterial pressure, followed by a fall; a diminution in blood flow in the femoral and carotid arteries and in the superior mesenteric vein, with a rise in the hydraulic impedance in these vascular beds. Discontinuance of the ether supply was followed by a rather rapid fall in venous pressure towards the original level; arterial pressures, flows, and impedances recovered rapidly.

With the subject in shock, the effects of deepening the anesthesia were similar to those in animals in good condition. During recovery, events were comparable but somewhat drawn out. An important difference from cyclopropane was evident here: Repeated deepening of the ether anesthesia was plainly deleterious; it hastened the development and increased the degree of shock, as measured by the increasing inability of the circulatory components to return to their preceding levels. As shock progressed under ether, the systolic blood pressure fell more rapidly than the diastolic, giving a continuously narrowing pulse pressure. The pulse pressure in dogs in good condition under ether was much wider than under evipal or cyclopropane.

Cyclopropane effects were as follows: With the subjects in good condition, on deepening the anesthesia, the central venous pressure rose remarkably and progressively. Arterial pressure showed inconstant changes. Heart rate progressively decreased. Femoral flow usually decreased, while that in the carotid and mesenteric beds increased; the hydraulic impedance changes were the inverse of the respective flows. Repeated deepening of anesthesia with cyclopropane, in contrast to ether, appeared to have no particularly lasting deleterious effects. In general, the changes on deepening the cyclopropane 
anesthesia in dogs in shock were comparable to those observed with the animal in good condition. A complete series of flow and pressure changes on recovery from deep cyclopropane anesthesia was observed and described. As shock progressed under cyclopropane, systolic and diastolic blood pressure fell at about the same rate, without a significant change in pulse pressure, until terminal stages were reached.

In so far as one can judge from these experimental observations on dogs in shock as well as in good condition, cyclopropane might offer a wider margin of safety for anesthesia in the seriously wounded than ether or sodium evipal with respect to blood pressure and blood flow through essential vascular beds.

\section{APPENDIX-A HEATED THERMOCOUPLE FLOWMETER ${ }^{5}$}

\section{H. STANLEY BENNETT, WILLIAM H. SWEET, AND DAVID L. BASSETT}

(From the Departments of Pharmacology and Anatomy of the Harvard Medical School)

This appendix describes a flowmeter for recording blood flow in cannulated vessels on anesthetized heparinized animals. The instrument records continuously and automatically, and is sufficiently simple in operation to allow flow to be measured in 3 separate vessels simultaneously, without necessitating the exteriorization of blood vessels or the use of hydraulic by-passes. It has been used in vessels ranging in size from the femoral of a cat to the portal vein of a dog. It could be installed in vessels either larger or smaller than those mentioned. The method appears to be worth publishing for 3 reasons: first, because it has proved to be practical and useful in a rather extensive series of experiments, as shown above; second, because its design eliminates or reduces many of the errors present in the thermostromuhr of Rein (20) and of Baldes and Herrick (21) (see Gregg et al. (22), Shipley et al. (23)); and third, because its development and use have brought to light some basic limitations and sources of inaccuracy in thermal methods of blood flow recording which have not been adequately pointed out, and which could profitably be added to the list discussed by Gregg (22) and by Shipley (23) and coworkers.

\section{Construction}

Heater. We have employed, in a modified form, the hot wire principle used by A. V. Hill (24), Anrep and coworkers (25), and Machella (26). This method depends on the fact that the temperature of a wire immersed in a

5 The development of this instrument was aided by a grant from the Milton Fund of Harvard University. moving stream of fluid or gas and heated by a constant current will depend on the rate at which heat is taken away from it by the moving stream, which in turn will be a function of velocity flow past the wire. The principle differs from that used by Rein (20) and by Baldes and Herrick (21), who heated a moving stream of blood between the 2 junctions of a thermocouple, external to a blood vessel.

The hot wire was a piece of nichrome wire 0.0015 inch $(0.0381 \mathrm{~mm}$.) in diameter and about $2 \mathrm{~mm}$. long, with a resistance of about 2 ohms, mounted rigidly in a cannula so as to be bathed by the moving stream of blood. The nichrome wire was heated by direct current drawn from a storage battery.

Thermocouple. Instead of recording the temperature changes in the wire by following changes in its resistance while it is connected as one arm of a bridge, we have soldered to it one junction of a thermocouple, in a manner somewhat like that used by Gibbs (27) and by Schmidt and Walker (28) and as recommended by Burton (29). The other junction of the couple was mounted on the opposite side of the same cannula, 1 to $4 \mathrm{~mm}$. upstream, so as to be kept as close as possible to blood temperature, and so as to be unaffected by blood heated while passing close to the hot wire. The thermocouple was in series with a moving coil galvanometer which registered the difference in temperature between the 2 junctions immersed in the blood. The deflections of the galvanometer were recorded optically.

The thermocouples were of wire 0.0015 inch $(0.038 \mathrm{~mm}$.) or 0.0031 inch $(0.0794 \mathrm{~mm}$.) in diameter. Three combinations of metals were tried: iron-constantan, copperconstantan, and chromel P-constantan. Iron-constantan couples were subject to breakage from corrosion. We were unable to establish any clear-cut preference between the other 2 combinations. The fine thermocouple wires were soldered to large (No. 28) copper leads, and these points of soldering were kept close together (but well insulated from each other) and enclosed in a small silver tube so as to keep them as nearly as possible at the same temperature and-thus avoid stray thermal currents arising from this extraneous pair of junctions.

Joining of heater and thermocouple. The hot junction of the thermocouple was soldered to a point midway along the length of the nichrome heater in such a way as to prevent the thermocouple circuit from being in parallel with any part of the hot wire. In a satisfactory junction, the heating current through the nichrome could be reversed without appreciably changing the deflection of the galvanometer in series with the couple.

Fashioning of hot and cold tips. The 4 wires leading to the hot junction (the 2 thermocouple wires and the 2 portions of the nichrome heater on each side of the junction) were then folded back so as to form a narrow tent or pyramid with the junction at the apex (Figure 13), and covered with a polymerizing phenolic insulating varnish (such as Bakelite) in which powdered quartz had been suspended in order to increase thermal conductivity. The 2 wires at the cold junction were similarly fashioned into a compact tip and insulated. 

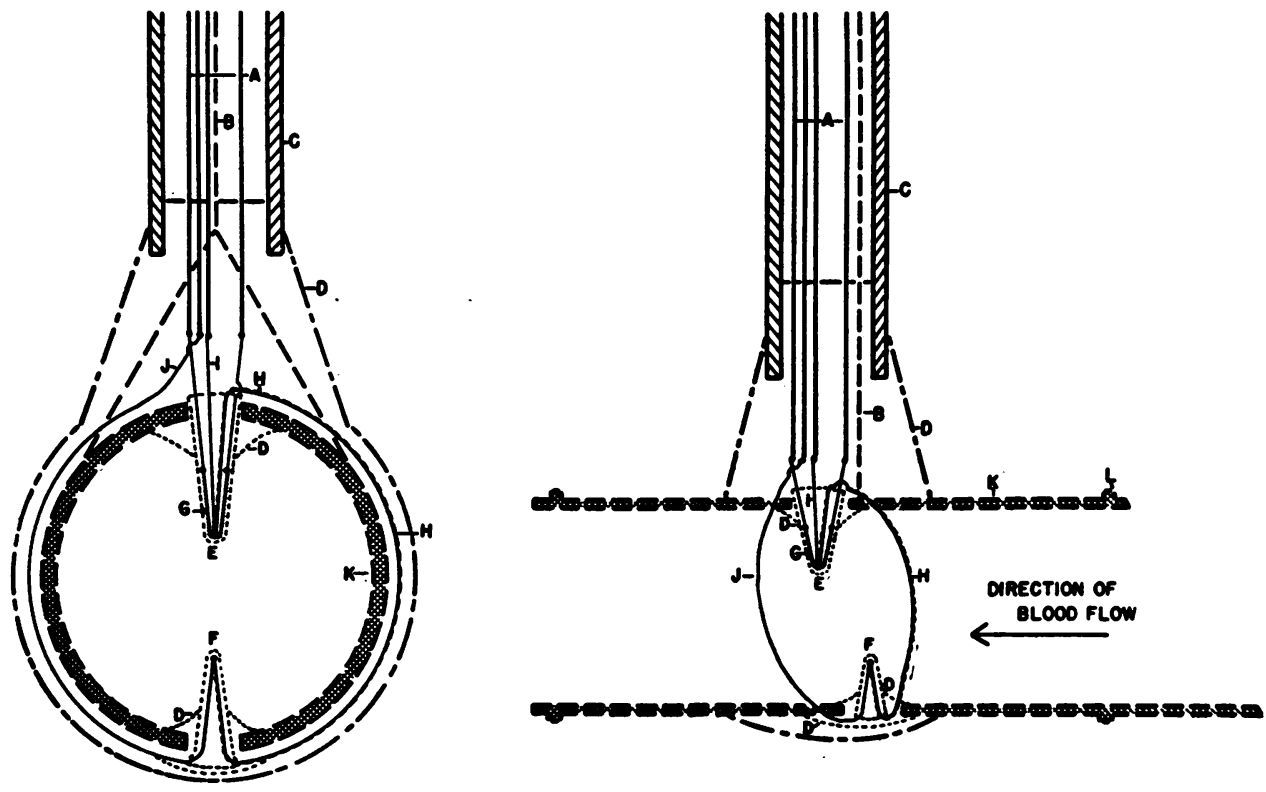

LECENO
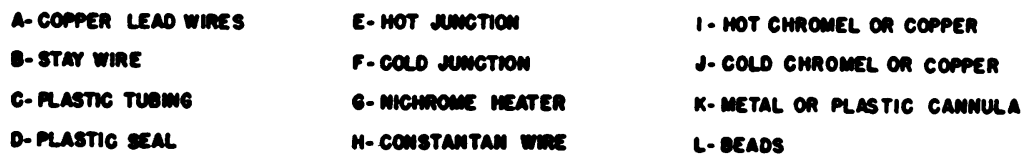

Fig. 13. Diagrammatic Cross Section and Longitudinal Section of Flowmeter Cannula with Thermocouple Tips Mounted in Position

Mounting in cannulae. The hot and cold tips connected to the lead wires were then mounted permanently and rigidly in a metal or lucite cannula, machined so as to fit conveniently into the vessel in which flow was to be measured. Metal was found to be superior to lucite because of its higher thermal conductivity. The tips were mounted as shown in Figure 13, each in a hole drilled through the wall of the cannula, with the actual thermal junctions projecting equally about one-third of the diameter into the lumen of the cannula, and with connecting wires passing around outside the cannula, as shown. . The tips were fastened in place with a polymerizing insulating varnish which also provided a continuous plastic lining to the cannula.

In order to avoid possible error from galvanic currents arising from salt action on 2 different wires or from the presence of a saline bridge between the hot and cold junctions or the wires looping around the cannula externally, all wires were well covered by a suitable non-hygroscopic polymerizing resin.

In order to relieve the electrical lead wires of mechanical stress, a steel stay wire was looped around the cannula and soldered or otherwise fastened to it. The lead wires were anchored securely to the stay wire near the cannula, and enclosed in stiff insulation for a distance of 2 or $3 \mathrm{~cm}$. from the cannula, in order to spare the fine wires from breakage from repeated flexion. The stay wire was insulated and the lead wires wound around it in a loose spiral, anchored with insulating varnish, and jacketed with flexible plastic tubing. Leads about $100 \mathrm{~cm}$. long were found convenient. All electrical wires were carefully insulated from the cannula and stay wire and from each other, except at the hot and cold junctions.

Provision for interchangeability. The 4 lead wires from each cannula were soldered at their free ends to a plug which could be connected interchangeably with any of 3 equivalent circuits. The free end of the stay wire was fastened to the plug in such a way as to take up tension before the electrical lead wires were pulled taut.

The resistance of each completed thermocouple was measured, and a supplementary manganin resistance coil (Figure 14, $F_{3}$ ) made up and mounted in the plug, the resistance of this coil being sufficient in the case of each thermocouple to bring the total resistance of the 2 elements to the same figure for all couples. In our thermocouples, the total resistance was 28.2 ohms.

Circuit. For simultaneous recording in 3 blood vessels, 3 approximately equivalent circuits were constructed as follows:

The nichrome heater (Figure 14, C) was connected through the plug and one end of a double-pole, doublethrow switch $\left(Q_{1}\right)$ to a low-discharge storage battery, a 1 ohm standard resistor, and a rheostat for adjusting the heater current, all in series. The current was measured 


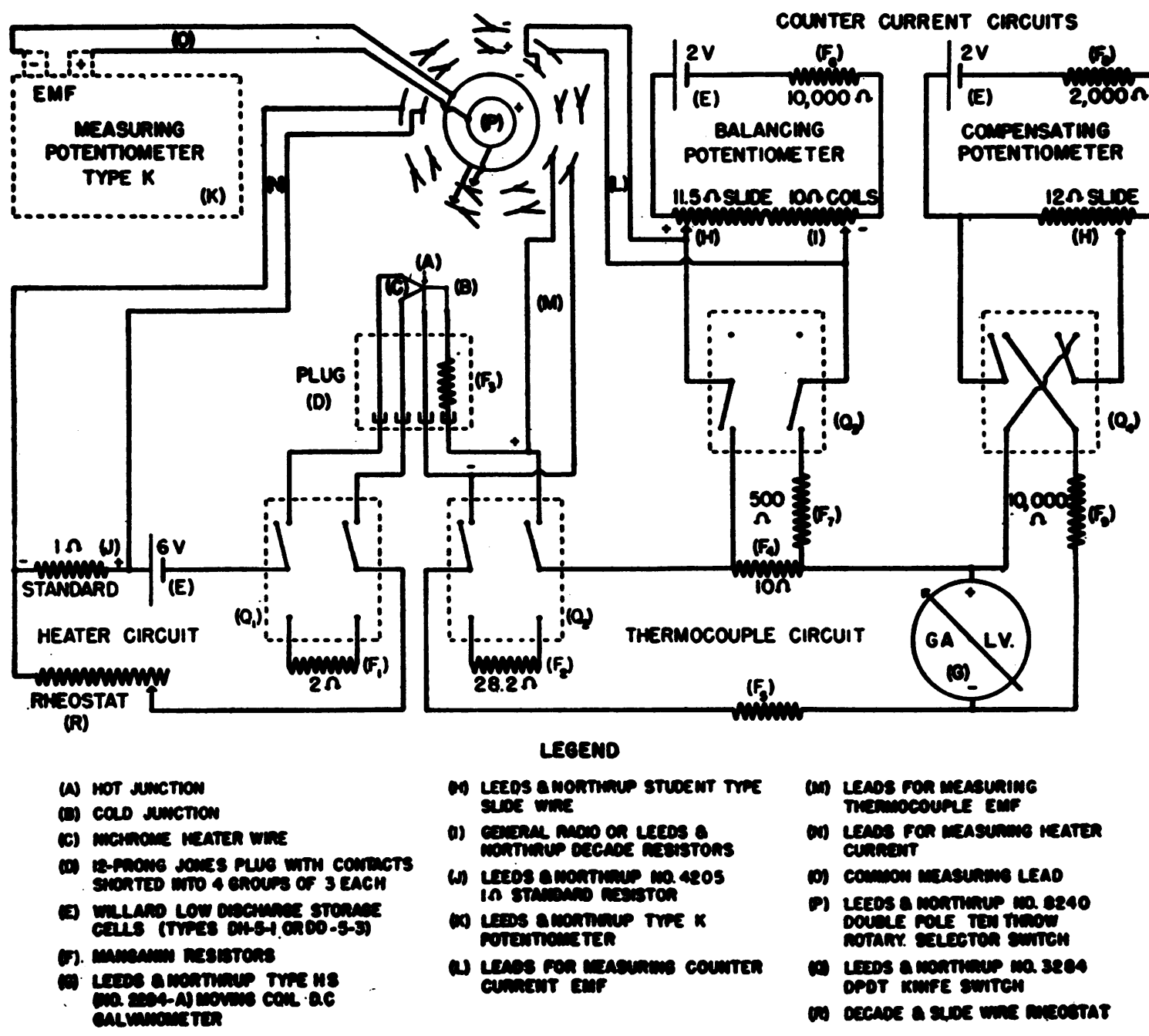

Fig. 14. Circuit Diagray

and standardized by determining the voltage drop across the $1 \mathrm{ohm}$ standard resistor $(\mathrm{J})$. Through the other end of the switch $\left(Q_{1}\right)$, the battery could be connected in series with a dummy heater resistance of 2 ohms $\left(F_{1}\right)$, through which it could be caused to discharge at the expected rate for a few hours before actual use so as to allow its voltage to become stabilized.

The thermocouple leads were likewise connected through a similar switch $\left(Q_{2}\right)$ in series with the galvanometer $(G)$ and certain resistors $\left(F_{4}\right.$ and $\left.F_{6}\right)$. These resistors were so chosen as to make the total resistance in series with the galvanometer equal to its critical damping resistance, as supplied by the manufacturer. The switch $\left(Q_{z}\right)$ contained provision for connecting the galvanometer in series with a dummy manganin resistance $\left(F_{2}\right)$ equal to that of the thermocouple, for test purposes.

A counter current tapped off from a balancing potentiometer in series with a 2 volt low discharge storage cell was connected as shown, in order to allow one to balance out the relatively large basic galvanometer deflection resulting from the heating of the hot junction, and to bring the beam back so that the desired fluctuations with flow will fall on the recording scale. The voltage to be tapped from the potentiometer to accomplish this was determined for each cannula in each circuit at the time of calibration and set at the determined figure at the beginning of each experiment and left constant.

In order to compensate readily for shifts in the zero point of the galvanometer and for variable stray parasitic thermal currents arising in the circuit or cannula, a compensating potentiometer was connected, as shown, through a reversing switch $\left(Q_{4}\right)$. With switches $Q_{1}$ and $Q_{3}$ open, and switch $Q_{2}$ connected to the thermocouple, extraneous thermal EMF's which might be present and causing error can be detected and nullified. It has been our practice to test rather frequently for these shifts and when necessary to use the compensating potentiometer to reset the galvanometer beam to its proper zero point while it is in 
series with the thermocouple, unaffected by heater or balancing current. The batteries providing power for the balancing and for the compensating potentiometers were kept on continuous discharge.

Provision was made for conveniently and accurately measuring the voltage tapped off from the balancing potentiometer, the voltage drop across the $1 \mathrm{ohm}$ standard in the heater circuit, and the actual thermocouple voltage, by means of a Leeds and Northrup Type $\mathrm{K}$ potentiometer, properly connected to its own battery, standard cell, and galvanometer. This measuring potentiometer $(\mathrm{K})$ could be readily connected to any of the leads from any of our 3 circuits by means of the rotary selector switch $(\mathrm{P})$.

The circuit was constructed with great care so as to conform in every possible respect with the standards necessary for reliable performance in critical low-voltage D.C. circuits. All permanent connections were carefully soldered, all resistors were of manganin, and all switches, lugs, connecting wires, etc., were selected so as to minimize the variations in resistance or voltages with temperature or other variables.

\section{Calibration}

The cannulae were calibrated with defibrinated beef blood, filtered through nylon bolting cloth, run by gravity pressure through the cannula, and measured in graduates. Calibration was carried out in a water bath at approximately $38^{\circ} \mathrm{C}$. Variations in bath temperature within the range of body temperature fluctuations did not affect the calibration.

The heater current necessary to give desired sensitivity and the counter current necessary to bring the galvanometer beam to bear on the recording scale were determined for each thermocouple in each circuit. The sensitivity of the couple could be adjusted by varying the heating current, high sensitivity being achieved by high heating currents. A sensitivity giving a galvanometer deflection of $2 \mathrm{~cm}$. for every doubling or halving of flow was found convenient for most cannulae.

In calibration, a series of various blood flows were passed through the cannula with heater and counter currents set, and deflections of the galvanometer noted. A sigmoid curve was obtained when voltage or galvanometer deflection was plotted against log of flow in cc. per second. The curves were conveniently plotted on semi-logarithmic paper, with voltage or deflection on the linear and flow on the logarithmic coordinates (Figure 15.t).

In calibration, a definite zero flow deflection, stable to within a few millimeters, was obtained and found to be repeatable in the animal. In this respect, the instrument differs from those of Baldes and Herrick (21) and of Rein (20), which have no definite zero flow deflection (Figure 15D) (see Herrick, Baldes and Sedgwick (30)). Zero flow equilibrium is achieved when the heat supplied by the heating current is taken away solely by conduction through the cannula and fluid, and by convection. Zero flow cannot be charted on semi logarithmic paper, but the deflection point was placed on the charts and assumed to be the point at which the curve becomes vertical. Galvanometer deflection decreased progressively as flow increased from zero.

Changes in counter current from the balancing or compensating potentiometers merely moved the calibration curve laterally along the voltage coordinates without distorting the curve in any way. Figure 15. A shows 2 curves taken with the same heating current with the same cannula, but with different counter currents-the number of millivolts tapped from the balancing potentiometer being given for each curve. Theoretically, the 2 curves should be entirely parallel, separated from each other by the same distance along the abscissa for any given ordinate. Calibration curves departing significantly from this ideal were discarded.

The part of the curve for fast flows is very steep, and was found to be less repeatable than other portions (Figure 15B). In practice, it was usually possible by proper choice of heating current to place this steep portion beyond the range of flows met with physiologically. The entire curve below this steep portion could be used satisfactorily. Very slow flows were met with only terminally in our experiments, and we found it convenient to calibrate our cannulae with a heating current sufficiently large to give a range of galvanometer deflections from zero to maximal flow too large to be encompassed by our recording scale, which was $12 \mathrm{~cm}$. wide. Accordingly we customarily made 2 curves with the same heating current but with different balancing currents (as in Figure 15A). It was possible to record almost all of the records on the high flow curve, the low flow curve being reserved for special purposes.

The calibration curves were repeatable and stable, and it was not necessary to calibrate each unit after or during each experiment. Figure 15B shows points from 6 calibration runs with straight forward flow on a single cannula, each run being taken on separate days, scattered over about a month's time. The small degree of scatter is evident. Also charted are points taken with pulsatile flow involving a phase of back flow, the amount of back flow being given for each point in terms of percentage of net forward flow. Points taken with back flow up to 40 per cent of net forward flow show no more scatter than the points taken with even forward flow. The reason for this is inherent in the structure of the thermocouples and their placement, and is discussed below. The curves were not affected by varying concentrations of red cells within limits met with in experimental animals, nor by changing the conductivity or the environment around the cannula in the bath, as by packing it in cotton, enclosing the cannula in a rubber tube, or leaving it free in the stirred fluid of the bath, as long as the temperature of the bath was the same as that of the blood used for calibration. With the heater currents used in practice, the maximal temperature of the hot junction at zero flow was 2 to $6^{\circ}$ above blood temperature, depending on the mass of metal and plastic close to the heater, and on the heater current. 


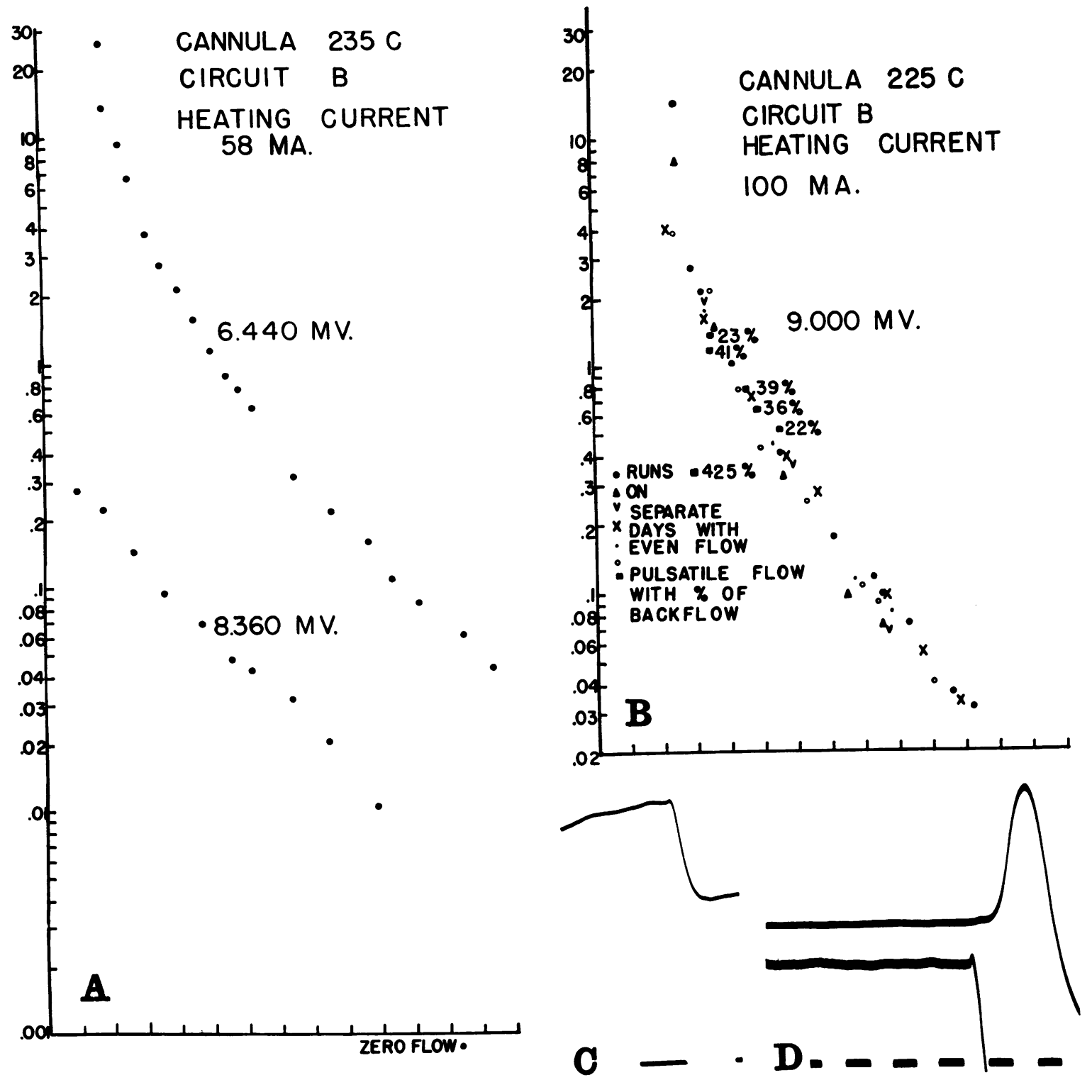

Fig. 15A. Calibration Curves of a Typical Cannula

Each curve was taken with the same heating current, but with different counter current-the voltage tapped from the balancing potentiometer being given in each case. Ordinates: Blood flow in $\mathbf{c m} .^{3}$ per second. Abscissae: Galvanometer deflection in $\mathrm{cm}$. One $\mathrm{mm}$. deflection is equivalent to about 0.5 microvolts of thermocouple voltage.

B. Calibration Points Taken with a Different Cannula, Showing the Amount of Scatter Obtained with 6 Different Runs with Straight Forward Flow and 1 Run with Phasic Flow Involving Back Flow

Each run was taken with the same heating and counter currents, but on different days, scattered over a month's time. Back flow is expressed in terms of percentage of net forward flow. Ordinates and abscissae as in Figure 15A.

\section{Record of Flow Through a Cannula to Show Speed of Response}

Note that the beam comes to rest within about 1.5 seconds of the time of producing a sudden change of flow through the cannula. Duration of time signal-3 seconds.

\section{Comparison of Speed and Directional Reliability of Response of This Flowmeter with Baldes Thermostromuhr}

The upper beam is the record of a Baldes unit in series with one of the present cannulae which is recording on the lower beam. At the spike artefact on the lower beam a sharp decrease in flow was produced, causing an immediate downward deflection of the beam recording from our instrument. The Baldes unit showed no change for a few seconds, and then gave a spurious deflection in the direction of increased flow, followed by a swing toward decreased flow. The small spike at the beginning of downswing in the lower record is an electrical artefact, induced from the coil of the signal magnet. Such effects can be avoided by shielding. Duration of time signal-3 seconds. 


\section{Time characteristics}

The mounted thermocouples had variable time characteristics: those with small tips mounted in metal cannulae with little excess insulation responded more rapidly than thermocouples with tips in lucite cannulae, or with rather bulbous plastic coverings. At fast flows, the thermocouples changed temperature very rapidly with changes in flow, the limiting factor in speed of response being the time lag of the critically damped galvanometer coil, which had a period of 1.5 seconds (Figure 15C).

At changes to slow flows, or when flow stopped, thermal equilibrium was achieved more slowly, as under these conditions an appreciable amount of fluid had to be heated. Because of the high heat capacity of water, the passage of an appreciable number of seconds was required before the heater could provide enough calories to heat up the water to the point where increased temperature difference between heater and fluid gave rise to an equilibrium involving loss of heat principally by conduction and convection. Thus, at slow flows or when flow stops, the limiting factor for speed of response is the thermal lag of the fluid surrounding the heater. The actual time required for complete equilibrium to be achieved when flow was suddenly stopped varied with the nature of the cannula and insulation, but ranged, in general, between 5 and 10 seconds.

\section{Cannulation}

The insertion of the cannulae requires that the vessels be dissected, the animal heparinized, the blood vessels clamped and cut open, the cannula inserted, filled with salt solution, and secured, and the flow through the vessel reestablished. As a rule, the total time during which the flow through any vessel was shut off for cannulation was from 1 to 3 minutes. This short time was made possible largely by the use of special ligature clamps made by drilling the ends of mosquito snaps as shown in Figure 16. Before cannulation, 2 waxed braided silk ligatures were passed around the vessel and threaded through the holes in the ligature clamp, as shown. After insertion of the cannula, the ligatures were drawn tight around each bead of the cannula and clamped. This required less time than would be required to tie knots. The flow was then reestablished in the vessel, final ties were secured around the cannula, and the clamps, which thus served a temporary purpose, were then removed.

\section{Performance and sources of error}

After cannulation, the thermocouple was plugged into the circuit and the heater and counter currents set at the figures determined in calibration. The precautions taken in choice of materials and batteries and in construction of the circuit were sufficient to give adequate stability of heater and counter currents, provided the heater battery was allowed to discharge at the expected rate for a few hours before actual use. Heater current and counter current voltage were checked from time to time during each experiment, and adjustments were rarely necessary.

However, the instrument was not entirely stable and

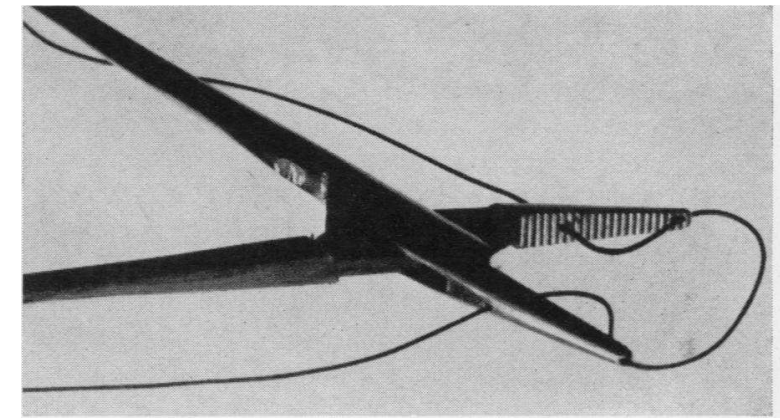

Fig. 16. Threaded Ligature Clamp Made by Drilling Mosquito SNaP

free from drift when used in animals. The bulk of the instability was traceable to the cannula and thermocouple itself. The feature of mounting the heater and thermocouple tips well inside the blood stream was adopted in order to free these elements as much as possible from temperature variations in the media surrounding the vessel. This feature has been only partially successful; apparently, there is some slight thermal conduction through the cannula wall and along the wires and insulation to the thermocouple junctions, for the deflection of the galvanometer could be influenced somewhat by changes in the temperature of the environment of the cannula. The influence of these variables was reduced by packing cotton around the cannula where it rested in the animal, by closing the wound snugly over it, and by covering the general area with cotton or blankets so as to keep the temperature as constant as possible.

Even these precautions did not suffice to eliminate drift entirely, and it was necessary to check for, and correct electrically, currents arising from varying ambient temperature by use of the compensating potentiometer and switches $Q_{1}$ and $Q_{3}$, as described under "Circuit." By correcting for these factors as frequently as the nature of the experiment demanded, it was possible to get flow records in which the amount of drift was known or corrected, with consequent improvement in accuracy. Each episode of checking involved disconnecting the thermocouple from heat and counter current, with a consequent swing of the galvanometer beam to a resting place near its zero point off the recording scale. After checking and, if necessary, resetting the zero point, closure of switches $Q_{1}$ and $Q_{3}$ brought the beam back to its proper recording position, leaving a short gap in the flow recording line corresponding to the time the galvanometer beam was off the scale. If resetting of the compensating potentiometer was necessary, a shift appeared in the projection of the reconstituted flow meter record. The degree of instability and drift ordinarily encountered, as revealed by this shift, can be seen in the flow records (Figures 6, 9). Quite possibly, error from varying environmental temperature might be further reduced by refinements in the placement and construction of the thermocouple tips. However, we feel other sources of inaccuracy are so large as not to justify any great experimentation along such lines. 
A further source of error arose from the fact that all portions of a moving blood stream may not be at exactly the same temperature. As shown by Franklin and McLachlin (31), blood from various tributary streams emptying into a larger vein may remain as separate and distinct "stream lines" for a considerable distance down the larger vein. Such a stream from a tributary vein draining surface tissues may be at a temperature different from a similar stream from deep tissues, and these 2 streams may varyingly influence the 2 junctions of the couple. Changes in the relative proportions of these components might produce galvanometer deflections which would not represent true flow changes.

This factor was troublesome at times in flow measurements in peripheral veins, such as the jugular and femoral. It has not been so troublesome in deep veins, such as the portal or mesenteric, or in arteries. It is not always possible to correct for this error by means of the compensating potentiometer, as inflow of cold blood from a surface vein, for example, may vary phasically with respiration, or may be changed sufficiently by pharmacological agents or other factors to make interpretation of the records extremely difficult.

Error can arise within the cannula if it be angulated with respect to the blood vessel leading into it, so that the rapid portion of the blood stream deflects against the hot junction, giving rise to an apparent flow recording which exceeds the true one. Conversely, if the stream is deflected against the wall of the cannula opposite the hot junction, the hot junction may find itself in a component of the stream moving more slowly than normally and record a falsely low flow. In practice, it has usually been possible to align the cannula so that this deflection error was small or absent. At times, however, especially in deep cavities, such good alignment has been difficult to maintain, and erroneous records have resulted. Error from angulation may be considerable in short, wide cannulae; it is negligible in cannulae which are long in relation to their diameter.

A further source of error arises from the fact that the rate at which heat is taken away from a heated wire by a moving stream of fluid does not bear a linear relation to velocity, whereas the EMF from a thermocouple and the resistance changes in a wire are very nearly linear functions of temperature changes within the limits of the application to blood flow measurements. Hence, the mean deflection obtained by a mechanical integration, by the galvanometer, of the thermal currents varying with phasic flow changes will not represent true mean flows over the corresponding period of time. The size of this deviation would vary with the nature and period of the phasic changes, but the test runs with the phasic flow in the calibration bath (Figure 15B) suggest that the error may be more of theoretical than of practical importance, as far as this instrument is concerned.

Gregg et al. (22) and Shipley et al. (23) pointed out that back flow during certain phases of diastole could cause great error in the Baldes thermostromuhr. Back flow in our flowmeter was of less consequence as a source of error than in the Baldes instrument since (1) the cold junction was mounted in a position where it was not affected by warmed blood washed back from the heater, and (2) heat was applied directly to the hot junction so that blood washed back on it still retained, initially at least, some heat from its recent forward passage past the couple, and hence cooled it less in back flow. As stated previously, phasic back flow up to 40 per cent of the net forward flow was tolerated by our instrument without appreciable error.

\section{General appraisal and comparison with other thermal methods}

This instrument was sufficiently stable to give calibration points with a scatter of about \pm 10 per cent or \pm 15 per cent above or below the mean flow in favorable portions of the curve (Figure 15B). This was better than we were able to achieve using comparable precautions with the Baldes apparatus (cf. Gregg et al. (22)).

However, in the animal, the instrument was less reliable, and the experimental data now available do not allow us to set any rigid limits as to its accuracy. Obviously, in the presence of angulation, or of marked difference in temperature between various components of the blood stream flowing through the cannula, or in the presence of fibrin clots, it may be totally inaccurate.

Under reasonably satisfactory operating conditions, when external temperature was not fluctuating too rapidly, when angulation was absent, and when the blood within the vessel was at even temperature, fairly consistent results were obtained, since (1) flow values in a given vessel, corrected for body surface of the animal, compared favorably with flows similarly taken and corrected from other animals under comparable conditions, and (2) flow measured in an artery was close to flow in the corresponding artery on the other side, or with flow in the corresponding vein. Good checks between artery and corresponding vein would appear to render unlikely any error from phasic changes or from back flow, which would scarcely be expected to affect both artery and vein alike or to the same degree. Examples of mean values of flows (with standard errors) in various vessels, obtained during a considerable series of experiments, are given in Table VII. These mean values are in fair agreement with corresponding figures obtained by other workers with other methods, but the fact that occasional flows were recorded well above or below the mean suggests that technical errors may at times be considerable. Similar discrepancies in comparing flows in corresponding vessels in the same animal were also sometimes encountered.

Our instrument utilized refinements in circuit construction beyond those used by Rein (20), Baldes and Herrick (21), Gibbs (27), and Schmidt and Walker (28). These refinements have been effective in improving the time characteristics, stability, and accuracy of the instrument. Attaching the thermocouple directly to the heater, as done by Gibbs (27) and Schmidt and Walker (28), gave a stable zero flow deflection, which was lacking from the instruments of Baldes and Rein, as pointed out by Herrick, Baldes, and Sedgwick (30). The influence of environmental changes in temperature, which contribute most 
markedly to the inaccuracy of the Baldes thermostromuhr (Gregg et al. (22); Shipley et al. (23)) and which would likewise affect the instrument of Rein (20) and of Schmidt and Walker (28) was greatly reduced in our instrument by mounting the thermocouples directly inside the blood stream. In addition, provision was made for nullifying error from this source when it was present. Errors in the Gibbs (27) method, arising (1) from changes in the caliber of the vessel, and (2) from possible shift of the needle tip from rapid axial portions of the blood stream to slower circumferential portions, were eliminated in the present instrument by mounting the thermocouples in a rigid cannula in a fixed and permanent position relative to the moving blood stream (in the absence of angulation). By reducing the amount of inert material around the heater and thermocouple, the time characteristics have been improved so that the limiting factor as to speed of response at fast flow changes is the mechanical inertia of the galvanometer, and at slow flow, the thermal lag of the surrounding fluid.

This considerable lag of response with changes to very slow flows or to stopped flows-the lag being a consequence of the high heat capacity of water-appears to be a hitherto unappreciated limitation of thermal flow recording in fluids. Machella (26) apparently allowed himself to be led into error from failure to consider this factor. He used a small heated nickel wire which would change temperature rapidly, and which would follow fast flow changes quite closely. His wire operated at about $6^{\circ}$ above blood temperature. When flow stopped, it was necessary for this wire to heat the surrounding blood to nearly this temperature before equilibrium could be achieved, and this would require an interval longer than the diastolic period. Hence, the instrument was inadequate for detecting stoppage of flow in the aorta in diastole, and his denial of this stoppage is not warranted. Shipley, Gregg, and Schroeder (8), who obtained evidence of diastolic stoppage or even back flow in the aorta using another method, were unable to explain the discrepancy between their results and those of Machella. The factors mentioned here would provide a possible explanation for this discrepancy.

\section{Basic limitation of thermal methods}

Because of the numerous attempts to develop instruments to record blood flow by thermal methods, with results never wholly satisfactory, it would seem advisable to list factors which limit the usefulness and accuracy of all thermal methods. Some of these factors have been pointed out before with respect to the particular instrument of Baldes and Herrick, by Gregg et al. (22) and Shipley et al. (23).

1. Thermal methods cannot be relied upon to record rapid phasic changes in flow in fluids involving phases of very slow flow or of complete stoppage. The thermal lag of fluid surrounding the heated element is such that several seconds may be required for equilibrium to be attained after flow stops.

2. Uneven temperature in various portions of a given blood stream in a vessel may be present to a degree suffi- cient to cause temperature changes in the heated element, falsely representing flow changes of considerable magnitude.

3. The temperature of the heated element does not bear a linear relationship to flow. Hence, when pulsatile flow changes are present, an integration of voltage or resistance changes by a recording system will not represent a true mean flow.

4. Fluid moving in either direction cools a heated element equally well, and hence, phasic back flow will record as forward flow.

These limitations, when combined with the great difficulty encountered in attempting to free completely the heated element from varying environmental factors, appear to be sufficient to render unlikely the development of a very satisfactory blood flow recording system utilizing the thermal principle.

\section{Summary}

A heated thermocouple flowmeter suitable for providing automatic and continuous recording of blood flow in cannulated vessels of anesthetized heparinized animals is described. The instrument is designed to eliminate or minimize certain factors producing error in previous thermal methods of flow recording. The advantages and limitations of the instrument are discussed and its performance is compared with that of other thermal flowmeters.

Certain basic limitations and sources of error inherent in all thermal methods of flow recording appear to be sufficient to render unlikely the development of a very satisfactory blood flow recording system utilizing the thermal principle.

\section{BIBLIOGRAPHY}

1. Green, H. D., Zero blood pressure level. Am. J. Physiol., 1941, 133, P 300.

2. Green, H. D., A glass membrane optical manometer. Federation Proceedings, 1942, 1, 32.

3. Werle, J. M., Cosby, R. S., and Wiggers, C. J., Observations on hemorrhagic hypotension and hemorrhagic shock. Am. J. Physiol., 1942, 136, 401.

4. Burton-Opitz, R., The vascularity of the liver. XI. The motor reaction in the portal radicles of the liver. Quart. J. Exper. Physiol., 1913, 7, 57.

5. Rein, H., Über die physiologischen Aufgaben des Adrenalins als Kreislaufhormon. Verhandl. d. deutsch. Gesellsch. f. Kreislaufforsch., 1937, 10, 27.

6. Katz, L. N., and Kolin, A., The flow of blood in the carotid artery of the dog under various circumstances as determined with the electromagnetic flowmeter. Am. J. Physiol., 1938, 122, 788.

7. Grindlay, J. H., Herrick, J. F., and Mann, F. C., Measurement of blood flow of the liver. Am. J. Physiol., 1941, 132, 489.

8. Shipley, R. E. Gregg, D. E., and Shroeder, E. F., An experimental study of flow patterns in various peripheral arteries. Am. J. Physiol., 1943, 138, 718. 
9. Das, S. C., The influence of sodium evipan on the heart and circulation. Quart. J. Exper. Physiol., 1941, 31, 103.

10. Mann, F. C., Essex, H. E., Herrick, J. F., and Baldes, E. J., The flow of blood in relation to anesthesia and operation. West. J. Surg., 1935, 43, 177.

11. McAllister, F. F., and Root, W. S., The circulatory responses of normal and sympathectomized dogs to ether anesthesia. Am. J. Physiol., 1941, 133, 70.

12. Evans, E. I., and Beecher, H. K., Unpublished observations, 1940.

13. Waters, R. M., Present status of cyclopropane. Brit. M. J., 1936, 2, 1013.

14. Seevers, M. H., and Waters, R. M., Pharmacology of the anesthetic gases. Physiol. Rev., 1938, 18, 447.

15. Krayer, O., and Beecher, H. K., Unpublished observations, 1938.

16. Volpitto, P. P., Woodbury, R. A., and Hamilton, W. F., Direct arterial and venous pressure measurements in man as affected by anesthesia, operation, and shock. Am. J. Physiol., 1939-1940, 128, 238.

17. Brace, D. E., Scherf, D., and Spire, L. J., The effect of cyclopropane on the blood pressure, stroke volume and heart size of the dog. Anesthesiology, 1941, 2, 261.

18. Blalock, A., Cardiac output in the dog during ether anesthesia. I. The effect of ether anesthesia on the cardiac output. Arch. Surg., 1927, 14, 732

19. Robbins, B. H., and Baxter, J. H., Jr., Studies of cyclopropane. IV. Cardiac output in dogs under cyclopropane anesthesia. J. Pharmacol. and Exper. Therap., 1938, 62, 179.

20. Rein, H., Die Thermo-Stromuhr. Ein Verfahren zur fortlaufenden Messung der mittleren absoluten
Durchflussmengen in uneröffneten Gefässen in situ. Ztschr. f. Biol., 1928, 87, 394.

21. Baldes, E. J., and Herrick, J. F., A thermostromuhr with direct current heater. Proc. Soc. Exper. Biol. and Med., 1937, 37, 432.

22. Gregg, D. E., et al., Observations on the accuracy of the thermostromuhr. Am. J. Physiol., 1942, 136, 250.

23. Shipley, R. E., Gregg, D. E., and Wearn, J. T., Operative mechanism of some errors in the application of the thermostromuhr method to the measurement of blood flow. Am. J. Physiol., 1942, 136, 263.

24. Hill, A. V., Electrical recording of the pulse. Lancet, 1920, 2, 752.

25. Anrep, G. V., Cruickshank, E. W. H., Downing, A. C., and Subba Rau, A., The coronary circulation in relation to the cardiac cycle. Heart, 1927, 14, 111.

26. Machella, T. E., The velocity of blood flow in arteries in animals. Am. J. Physiol., 1936, 115, 632.

27. Gibbs, F. A., A thermoelectric blood flow recorder in the form of a needle. Proc. Soc. Exper. Biol. and Med., 1933, 31, 141.

28. Schmidt, C. F., and Walker, A. M., A thermostromuhr operating on storage battery current. Proc. Soc. Exper. Biol. and Med., 1935, 33, 346.

29. Burton, A. C., Appendix: theory and design of the thermostromuhr. J. Appl. Physics, 1938, 9, 127.

30. Herrick, J. F., Baldes, E. J., and Sedgwick, F. P., Experimental analysis of Rein's thermostromuhr for small flows. J. Appl. Physics, 1938, 9, 124.

31. Franklin, K. J., and McLachlin, A. D., Streamlines in the abdominal vena cava. J. Physiol., 1936, 86, 386. 